\title{
RNAi AND mIRNA PATHWAYS IN MAMMALS II - BIOLOGICAL ROLES
}

Keywords: dsRNA, siRNA, miRNA, Dicer, TARBP2, PACT, Argonaute

\section{PETR SVOBODA}

Institute of Molecular Genetics, Academy of Sciences of the Czech Republic, Videnska 1083, 14220 Prague 4, Czech Republic

Correspondence to: Petr Svoboda, Institute of Molecular Genetics ASCR, Videnska 1083, 14220 Prague 4, Czech Republic, tel. \#+420 241063147, e-mail: svobodap@img.cas.cz.

\begin{abstract}
RNA silencing denotes sequence-specific repression mediated by small RNAs. In mammals, there are two closely related pathways, which share several protein factors: RNA interference (RNAi) and microRNA (miRNA) pathway. The miRNA pathway regulates endogenous protein-coding gene expression. It has been implicated in many biological processes and majority of mammalian genes appear to be directly or indirectly exposed to miRNA-mediated regulations. RNAi generally serves as a form of innate immunity targeting viruses and mobile elements, although it occasionally also acquired function in protein-coding gene regulation. The function of RNAi in mammals is still poorly understood but it is clear that proteins supporting RNAi are also involved in miRNA biogenesis and function. Because of the large volume of the existing literature, the review of mammalian miRNA and RNAi pathways was divided into two parts, where first one reviewed components of the pathways and the second one, presented here, reviews roles and significance of the pathways.
\end{abstract}

\section{Introduction}

In the first part of the review off mammalian RNAi and miRNA pathways, I focused on mechanistic description of the pathways. Here, I will provide an overview of biological roles and biological phenomena associated with mammalian RNAi and miRNA pathways (Fig. 1).

\section{miRNA-mediated control of gene expression - important functional aspects}

The current miRBase (Kozomara and Griffiths-Jones, 2014) edition 22.1 annotates 1917 human miRNA loci that give rise to 2654 annotated miRNAs. There are 1234 precursors and 


\section{mammalian somatic cells}

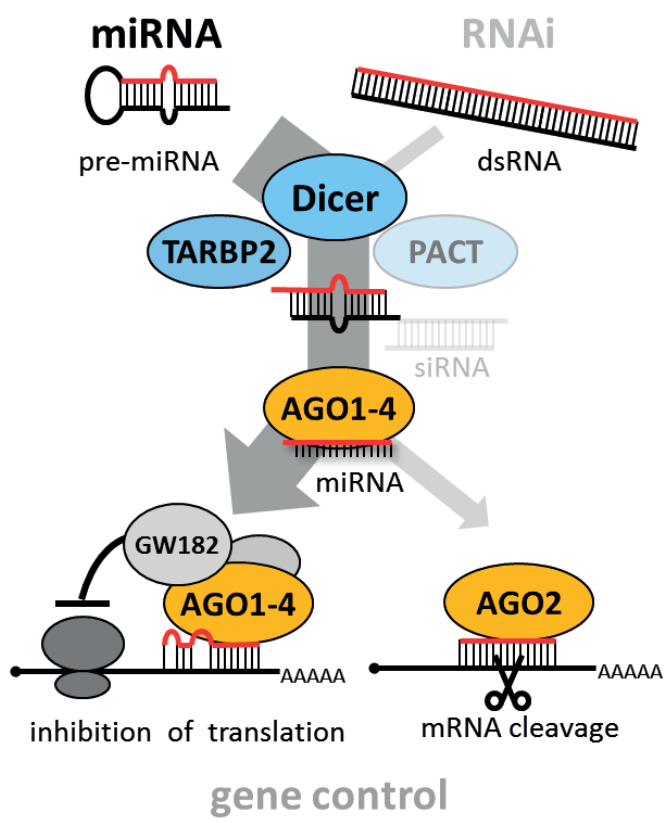

Figure 1 Mechanistical merging of miRNA and RNAi pathways in mammals

1978 mature miRNAs annotated in mouse. A simple connection of these counts with the fact that only nucleotides $2-8$ of a miRNA are sufficient for target recognition and suppression implies that miRNA-mediated repression is a widespread and extremely evolvable regulatory system for gene expression. At the same time, one should not forget the above-mentioned stoichiometry between miRNAs and their target sites that is needed for efficient silencing.

Evolution of miRNAs is fast - there are only a few miRNAs conserved between Drosophila and mammals. Given the diversity of canonical and non-canonical miRNAs, it is conceivable that miRNAs to emerge from random formation of Drosha/Dicer substrates. Newly evolving miRNAs likely form a considerable portion of annotated miRNAs, especially in species where miRNAs are deeply sequenced and low-abundant miRNAs are identified.

According to the evolutionary theory, new miRNAs would either acquire function and become fixed during evolution or they would be lost. In addition, the target repertoire of existing miRNAs can also rapidly evolve since a single point mutation can weaken an existing regulation or create a new one. This idea is consistent with the data showing that mammalian mRNAs are under selective pressure to maintain and/or avoid specific 7-nucleotide seeding regions (Farh et al., 2005). It can be nicely exemplified on the Texel sheep phenotype where a single mutation creating a novel miRNA target site in myostatin causes the exceptional meatiness of this breed (Clop et al., 2006). 
The set of miRNAs in each cell type forms a combinatorial post-transcriptional regulation system stabilizing gene expression pattern. miRNAs have widespread impact on expression and evolution of protein-coding genes (Farh et al., 2005). The number of mRNAs that have functionally important interaction with miRNAs (i.e. suppression of this interaction yields a phenotype) in a studied model system is presumably small and certainly difficult to discern among the possible interactions. Thus, every search for functionally important interactions between miRNAs and their targets has to face the fact that miRNAs represent a dynamically evolving system with countless random interactions, which are not biologically relevant.

\section{Extracellular microRNAs}

An interesting research field developed around the release of miRNAs from cells, detection of extracellular miRNAs, and transfer between cells. Importantly, the vast majority of the references provided descriptive and correlative data documenting presence of circulating miRNAs under different conditions (e.g. (Arroyo et al., 2011; Bellingham et al., 2012; Huang et al., 2013b; Luo et al., 2009; Novellino et al., 2012; Turchinovich et al., 2011). I will not review the bulk of the circulating RNA literature, which provides data concerning biomarker potential of circulating miRNAs, undoubtedly of extreme clinical relevance but of minimal relevance for this review. Below, I summarize results, which admittedly raise more questions than provide satisfactory answers.

Small RNAs can be transmitted from one cell to another under physiological conditions, as evidenced, for example, by systemic RNAi in arthropods or plants. Small RNAs can utilize dedicated transporters, common communication channels, or secretory vehicles. It was also reported that Gap junctions can serve for miRNA transfer from microvascular endothelial cells to colon cancer cells (Thuringer et al., 2016). Circulating mammalian miRNAs were reported 2008 when they were found in serum of lymphoma patients; they were immediately recognized as potential non-invasive biomarkers for cancer diagnostics and treatment (Lawrie et al., 2008). The same year, placental miRNAs were found circulating in maternal plasma (Chim et al., 2008), which was one of the discoveries leading to the notion that miRNAs could be a mobile regulating molecule (Iguchi et al., 2010) and that could even mediate transgenerational epigenetic heritance (Sharma, 2015) or be transmitted across species (Buck et al., 2014; Zhang et al., 2012). Since then, extracellular miRNAs were identified in a broad range of biological fluids, including plasma, aqueous humour, cerebrospinal fluid, nasal mucus, or milk (Baglio et al., 2015; Dismuke et al., 2015; Huang et al., 2013b; Izumi et al., 2015; Kropp et al., 2014; Pegtel et al., 2011; Wu et al., 2015a). miRNAs were identified in the cargo of exosomes, membranous vesicles 40 to $100 \mathrm{~nm}$ in diameter, which are constitutively released by almost all cell type and are found essentially in every biological fluid (reviewed, for example, in Rak, 2013; Yoon et al., 2014)

However, extracellular miRNAs do not need to be necessarily encapsulated in extracellular vesicles, as two studies showed that $95-99 \%$ of extracellular miRNA are not in extracellular vesicles but associated with AGO proteins in serum and cell culture media (Arroyo et al., 2011; Turchinovich et al., 2011). Furthermore, most individual exosomes in standard 
preparations do not seem to contain biologically significant numbers of miRNAs (Chevillet et al., 2014). The molecular mechanism of miRNA release, either as a cargo in a vesicle or free, is poorly understood and the current knowledge does not allow for building a coherent model as the literature is scarce. Non-templated nucleotide additions were found to distinguish between cellular miRNAs, which were 3' end adenylated in cells whereas 3' end uridylated isoforms appeared overrepresented in exosomes suggesting a possible role of 3 ' terminal modifications in sorting miRNAs into extracellular vesicles (Koppers-Lalic et al., 2014). Recently, ALIX, an accessory protein of the endosomal sorting complex, it has been implicated in sorting miRNAs into extracellular vesicles based on its interaction with $\mathrm{AGO} 2$ and reduced miRNAs levels in extracellular vesicles upon Alix knock-down (Iavello et al., 2016).

Importantly, any model where miRNAs would be carried over to regulate gene expression by the canonical miRNA activity must face the kinetic data mentioned above (Wee et al., 2012). While one cannot exclude a non-canonical signalling function of circulating miRNAs (which has not been conclusively demonstrated yet), the literature on circulating RNAs may include misleading statements, which are unsupported by experimental evidence.

Taken together, while existence of circulating miRNAs has been demonstrated beyond a doubt, experimental evidence for their function (if any) is not conclusive. Exosomal vesicles can carry miRNAs and siRNAs - in the latter case, exosomes were adapted for a delivery tool for siRNAs, which has a good potential for further development of siRNA therapy (El-Andaloussi et al., 2012; Kumar et al., 2015; Lasser, 2012; Lee et al., 2012; Nguyen and Szoka, 2012; Shtam et al., 2013; Wahlgren et al., 2012; Wahlgren et al., 2016).

\section{RNAi pathway in mammals- important functional aspects}

It should reiterated that the, "so-called" RNAi knock-down with siRNAs in mammalian cells is essentially using the miRNA pathway with retained the ability to cleave perfectly complementary targets by AGO2. The mammalian canonical RNAi (i.e. long dsRNA-driven) is a dormant pathway, at best. By that is meant that the protein factors present in every mammalian cells (Dicer, TARBP2, and AGO2) are competent to support RNAi but long dsRNA does not efficiently induce RNAi in most mammalian cells (Nejepinska et al., 2012). This notion is supported by the reconstitution of human RNA interference in budding yeast demonstrates that Dicer, TARBP2, and AGO2 are sufficient to functionally reconstitute RNAi (Suk et al., 2011). This demonstrates that these three proteins constitute the essential core of RNAi mechanism although RNAi is not properly reconstituted when bona fide RNAi precursors were co-expressed (Wang et al., 2013). The problem is apparently at the level of Dicer processing as the human slicer AGO2 RNAi role is so conserved that it could function in RNAi in the early divergent protozoan Trypanosoma brucei, demonstrating conservation of basic features of the RNAi mechanism (Shi et al., 2006). In an analogous experiment, human AGO2 could not replace Arabidopsis thaliana AGO1 in the miRNA pathway (Deveson et al., 2013). In a sense, these different results are not that surprising considering the minimal requirements for RNAi and the complexity of the miRNA pathway, which provides a larger space for evolution of incompatible adaptations. 
However, there are some cases indicating that RNAi is still active in mammals and, under unique circumstances, may be even an essential pathway.

The main bottleneck for canonical RNAi in mammals is efficient production of siRNAs from long dsRNA, which is poor in most mammalian cells (Flemr et al., 2013; Nejepinska et al., 2012). However, several reports showed that induction of RNAi with intracellular expression of long dsRNA can be achieved in transformed and primary somatic cells (Diallo et al., 2003; Elbashir et al., 2001; Gan et al., 2002; Shinagawa and Ishii, 2003; Tran et al., 2004; Yi et al., 2003). These data imply that RNAi can occur if there is a sufficient amount of long dsRNA, which is directed preferentially to RNAi but not into other dsRNA pathways. Under these circumstances, the limiting factor is just Dicer's ability to produce siRNA (Flemr et al., 2013).

\section{Endogenous RNAi in the germline}

\section{Retrotransposon repression in mouse oocytes}

RNAi-mediated mobile element silencing has also been documented in the mouse germline (Tam et al., 2008; Watanabe et al., 2006; Watanabe et al., 2008). Mutations in the piRNA pathway components are detrimental to sperm development, suggesting that piRNAs are the dominant class of small RNAs controlling mobile element activity in the male germline (reviewed in Toth et al., 2016). In contrast, female mice lacking functional piRNA pathway are fertile with no obvious defects in oocytes (Carmell et al., 2007). Endo-siRNAs suppress TEs silencing in mammalian oocytes as documented by derepression of some retrotransposons in oocytes depleted of Dicer or AGO2 (Murchison et al., 2007; Watanabe et al., 2008). As already proposed for invertebrates, the piRNA and endo-siRNA pathways likely cooperate in creating a complex silencing network against mobile elements in the mammalian germline. Long terminal repeat MT elements and SINE elements are strongly upregulated in Dicer ${ }^{-/}$oocytes, while the levels of IAP transposon are elevated in the absence of MILI protein but not in Dicer/- oocytes (Murchison et al., 2007; Watanabe et al., 2008). Still many loci composed of other types of TEs, e.g. LINE retrotransposons, give rise to both piRNAs and endo-siRNAs, again suggesting that the biogenesis of these small RNAs is interdependent. The role of endogenous RNAi in TE silencing extends from germ cells to preimplantation embryo stages. Apart from maternally derived piRNAs and endo-siRNAs, which persist in the embryos for a large part of preimplantation development, zygotic endo-siRNAs are generated de novo mainly to control the activity of zygotically activated MuERV-L retrotransposon (Ohnishi et al., 2010; Svoboda et al., 2004). SINE-derived endo-siRNAs also increase in abundance in early embryo stages, which is consistent with the observation that B1/Alu SINE endo-siRNAs account for a vast majority of endo-siRNAs sequenced from mouse ES cells (mESCs) (Babiarz et al., 2008). Whether these SINE endo-siRNAs play an active role in TE silencing in mESCs similarly to other TE-derived endo-siRNAs in oocytes remains to be determined. RNAi-dependent silencing of LINE transposons has also been described in cultured HeLa cells, where endo-siRNAs derived from bidirectional transcripts of sense and antisense L1 promoter were proposed to control L1 activity (Yang and Kazazian, 2006). Although some evidence for retrotransposon-derived endo-siRNAs 
from mammalian somatic cells was obtained from deep sequencing data (Kawaji et al., 2008), a convincing support for the function of endo-siRNAs in TE silencing in mammalian somatic tissues, has yet to be provided.

\section{Control of endogenous genes in mouse oocytes}

In mice, perturbation of the endo-siRNA pathway in oocytes is responsible for severe meiotic defects and resulting female infertility. Targeted oocyte-specific knockout of both Dicer and $A g o 2$ lead to similar phenotypes including chromosome misalignment and defective spindle (Kaneda et al., 2009; Murchison et al., 2007; Tang et al., 2007). These effects were originally attributed to the loss of maternal miRNAs. However, miRNA pathway is suppressed in mouse oocytes and oocytes lacking $D g c r 8$, which is required for canonical miRNA biogenesis, can be fertilized and do not show any significant disturbance of the transcriptome (Ma et al., 2010; Suh et al., 2010). This means that the canonical miRNA pathway is non-essential and largely inactive in mouse oocytes despite intact biogenesis of miRNAs (Fig. 2). In fact, the spindle phenotype is caused by the loss of a highly active RNAi pathway in mouse oocytes. High-throughput analysis of small RNAs in mouse oocytes revealed a unique class of endo-siRNAs derived from processed pseudogenes (Tam et al., 2008; Watanabe et al., 2008). Transcriptomes of oocytes lacking Dicer and Ago2 (including oocytes expressing catalytically-dead AGO2) are similarly affected (Kaneda et al., 2009; Stein et al., 2015). At the same time, genes matching pseudogene-derived endo-siRNAs are enriched in the group of upregulated genes in both knockouts (Kaneda et al., 2009; Stein et al., 2015; Tam et al., 2008; Watanabe et al., 2008).

In addition, putative endo-siRNA targets are enriched in cell cycle regulators and genes involved in microtubule organization and dynamics (Tam et al., 2008). These findings suggest that regulation of protein-coding genes by endo-siRNAs controls the equilibrium of protein factors required for proper spindle formation, chromosome segregation and meiosis progression in mouse oocytes. As pseudogenes are rapidly evolving source of dsRNA for endo-siRNA production, it will be interesting to investigate whether the role of RNAi in spindle formation during meiotic maturation of oocytes is conserved in mammals.

The reason for high levels of endo-siRNAs and the high RNAi activity in mouse oocytes is the aforementioned truncated Dicer isoform that lacks the N-terminal helicase domain (Flemr et al., 2013) (Fig. 2). It efficiently generates siRNAs from long dsRNAs, and is sufficient for enhancing RNAi in cultured cells while its loss in mouse oocytes yields the same phenotype as conditional knock-outs of Dicer or Ago2 (Flemr et al., 2013).

Endo-siRNAs have also been proposed to contribute to the self-renewal and proliferation of mouse embryonic stem cells (mESCs), since the proliferation and differentiation defects observed in Dicer-/- mESCs are more dramatic than in $\mathrm{Dgcr}$ 8-/ $^{-/}$mESCs (Kanellopoulou et al., 2005; Murchison et al., 2005; Wang et al., 2007). A population of endo-siRNAs derived mostly from hairpin forming B1/Alu subclass of SINE elements was identified in mESCs (Babiarz et al., 2008). Fragments of SINE elements are commonly present in untranslated regions of protein-coding transcripts and it is therefore possible that SINE-derived endo-siRNAs participate in posttranscriptional gene silencing in mESCs. However, this hypothesis has not been tested experimentally. 


\section{mouse oocytes}

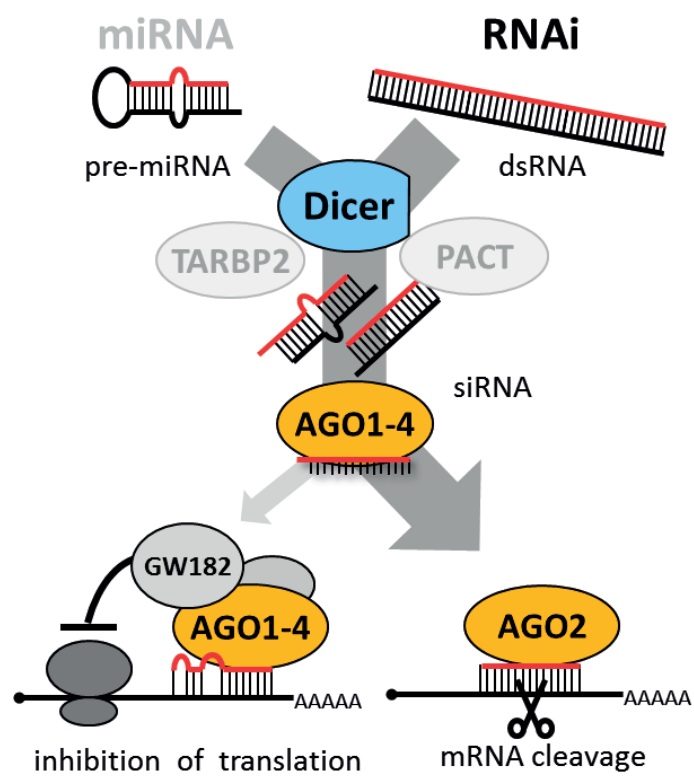

gene control \& defense

Figure 2 miRNA \& RNA arrangement in mouse oocytes

\section{Endogenous RNAi in the soma}

Little evidence is available for potential role of endo-siRNAs in the regulation of protein-coding mRNAs in mammalian somatic tissues. The natural antisense transcription in somatic cells, which has a potential to generate dsRNA, yields low levels of endo-siRNAs, whose biological relevance is questionable. At the same time, endo-siRNAs derived from natural antisense transcripts of Slc34a gene were identified in mouse kidney, where $\mathrm{Na}$ /phosphate cotransporter exerts its physiological function (Carlile et al., 2009). However, changes in expression levels of Slc34a upon suppression of the endo-siRNA pathway have not been addressed. In mouse hippocampus, deep sequencing revealed a set of potential endo-siRNAs generated from overlapping sense/antisense transcripts and from hairpin structures within introns of protein-coding genes (Smalheiser et al., 2011) . The most abundant endo-siRNAs from SynGAPl gene locus were also found in complexes with AGO proteins and FMRP in vivo. Interestingly, a large part of potential hippocampal endo-siRNA targets encode for proteins involved in the control of synaptic plasticity and the number of endo-siRNAs derived from these gene loci increased significantly during olfactory discrimination training (Smalheiser et al., 2011). Given the fact that vast majority of identified endo-siRNA sequences mapped to intronic regions, the endo-siRNAs could 
act co-transcriptionally on nuclear pre-mRNAs, perhaps similarly to the mechanism of RNAi-mediated inhibition of RNA Pol II elongation described in C. elegans (Guang et al., 2010). Alternatively, endo-siRNAs could control correct distribution of target mRNAs as unspliced pre-mRNA can be exported from the neuronal nucleus and transported to dendrites for processing (Glanzer et al., 2005). In any case, these findings open an attractive hypothesis that endo-siRNAs participate in synaptic plasticity during learning process and the neuronal endo-siRNA pathway might be also linked to various neurodegenerative disorders (Smalheiser et al., 2011).

\section{Antiviral RNAi}

In contrast to nematodes and insects, data supporting involvement of mammalian RNAi in antiviral defense is weak (reviewed in detail in Cullen, 2006; Cullen et al., 2013). It is unlikely that RNAi substantially acts as an antiviral mechanism in mammals where long dsRNA induces a complex sequence-independent antiviral response, commonly known as the interferon response (reviewed in Gantier and Williams, 2007). Consistent with this, no siRNAs of viral origin have been found in human cells infected with a wide range of viruses (Pfeffer et al., 2005). Occasional observations, such as detection of a single siRNA in HIV-1 infected cells (Bennasser et al., 2005) does not provide any conclusive evidence that RNAi is processing viral dsRNA and suppresses viruses under physiological conditions in vivo.

It must be stressed that circumstantial evidence suggesting the role of RNAi in viral suppression must be critically examined and interpreted. One has to keep in mind, for example, that data, which appear as evidence for viral suppression by RNAi, could reflect miRNA-mediated effects. Since viruses co-evolve with different hosts and explore all possible strategies to maintain and increase their fitness, it is not surprising that viral reproductive strategies come into contact with mammalian RNA silencing pathways, particularly the miRNA pathway, which shares components with the RNAi pathway. For example, EpsteinBarr virus (EBV) and several other viruses encode their own miRNAs (Parameswaran et al., 2010; Pfeffer et al., 2005; Pfeffer et al., 2004; Sullivan et al., 2005) or take advantage of host cell miRNAs to enhance their replication (Jopling et al., 2005).

Another evidence for an interaction between viruses and RNA silencing is the presence of putative suppressors of RNA silencing (SRS) in various viruses. As viral genomes rapidly evolve, SRS should be functionally relevant. For example, B2 protein in Nodaviruses (e.g. FHV) is essential for replication, inhibits Dicer function, and B2-deficient FHV can be rescued by artificial inhibition of RNAi response ( $\mathrm{Li}$ et al., 2002). B2 protein also enhances the accumulation of Nodaviral RNA in infected mammalian cells (Fenner et al., 2006; Johnson et al., 2004). Other potential SRS molecules have been identified in viruses infecting vertebrates, such as Adenovirus VA1 noncoding RNA (Lu and Cullen, 2004), Influenza NS1 protein (Li et al., 2004), Vaccinia virus E3L protein (Li et al., 2004), Ebola virus VP35 protein (Haasnoot et al., 2007), TAS protein in primate foamy virus (Lecellier et al., 2005), or HIV-1 TAT protein (Bennasser et al., 2005).

The existence of SRS in viruses infecting mammals does not prove that these viruses are targeted by mammalian RNAi. First, viruses may have a broader range of hosts (or vectors), 
including, e.g. blood sucking insects. Thus, a virus can be targeted by RNAi in one host and by another defense mechanism in another one. For example, the Dengue virus, whose life cycle takes place in humans and mosquitoes, is targeted by RNAi in mosquitoes and it likely evolved an adaptation to circumvent RNAi (Sanchez-Vargas et al., 2009). Second, viral SRS in mammalian cells may have other purpose than counteracting viral suppression by RNAi. Since biogenesis and mechanism of action of mammalian miRNAs overlaps with RNAi, it is possible that the role of such SRS is to modify cellular gene expression by suppressing the activity of miRNAs. Third, the main effect of SRS may be aimed at other defense mechanisms recognizing and responding to dsRNA and, as a consequence, SRS effects on RNAi are observed.

\section{Systemic RNAi in mammals}

Non-cell autonomous RNA with an extent similar to that of C. elegans or in some insects is highly unlikely to function in vertebrates. However, a limited environmental or systemic RNAi may exist there as the homologs of sid- 1 have been found in all sequenced vertebrate genomes (Jose and Hunter, 2007). Two sid-1 homologs (SidT1 and SidT2) are present in mice and humans with a documented role for SidT1 in dsRNA uptake in humans (Duxbury et al., 2005; Wolfrum et al., 2007). Furthermore, experimental overexpression of human SidT1 significantly facilitated cellular uptake of siRNAs and resulted in increased RNAi efficacy (Duxbury et al., 2005). As it will be discussed later, the mammalian immune system employs a number of proteins responding to dsRNA independently of RNAi (Gantier and Williams, 2007), while RNAi does not seem to participate in the innate immunity (Cullen, 2006; Cullen et al., 2013). Thus, the primary role of a dsRNA uptake mechanism in mammals is likely not involving RNAi even though it could have served such a role in an ancestral organism.

\section{Nuclear function of small RNAs}

The literature search yielded a large heterogeneous group of publications concerning nuclear localization of Dicer and AGO proteins as well as nuclear effects, including transcriptional gene silencing. Some of these observations might come from physiologically relevant nuclear silencing mechanisms. However, when critically evaluating published studies, not enough evidence was found, to establish a model for transcriptional silencing in mammals; except of the PIWI-induced transcriptional silencing in the germline (REF). Here, I will provide an overview of nuclear aspects of RNA silencing and highlight those observations which might be related to the miRNA pathway or long dsRNA response.

Homology-dependent phenomena and observations that may reflect nuclear mechanisms involving small RNAs can be sorted into several areas, which will be discussed further below:

Indirect effects of miRNAs on chromatin

Nuclear RNAi (nuclear post-transcriptional silencing)

Transcriptional regulations (stimulation/repression) by exogenous small RNAs 
Transcriptional regulations (stimulation/repression) by miRNAs

27-nt RNA-mediated regulation of endothelial nitric oxide synthase gene

Splicing regulation by small $R N A$ s

$D N A$ repair-associated small $R N A s$

First, it is necessary to discuss nuclear localization of miRNA and RNAi factors, since their nuclear localization is a pre-requisite for nuclear silencing. Pioneering RNAi work indicated that silencing occurs in the cytoplasm because dsRNA against intronic sequences had no silencing effect (Fire et al., 1998) and the RISC complex co-purified with ribosomes (Hammond et al., 2000). Early studies in mammalian cells also suggested that RNAi is cytoplasmic (Billy et al., 2001; Zeng et al., 2002). However this notion was subsequently challenged by a series of studies reporting nuclear RNAi and small RNA-induced transcriptional silencing (Morris et al., 2004; Robb et al., 2005; Ting et al., 2005).

\section{Nuclear localization of Dicer}

A number of works directly or indirectly implies nuclear localization of Dicer (Doyle et al., 2013; Drake et al., 2014; Gagnon et al., 2014a; Gullerova and Proudfoot, 2012; Haussecker and Proudfoot, 2005; Neve et al., 2016; Ohrt et al., 2012; Sinkkonen et al., 2010; White et al., 2014), which contrasts with a recent in vivo study on mouse Dicer where tagging of an endogenous Dicer gene with an antibody epitope yielded exclusively cytoplasmic localization in all analyzed tissues with an extremely sensitive detection limit for nuclear Dicer (Much et al., 2016). Thus, despite the collection of the reports below, one should still approach the nuclear aspect cautiously. One of the earlier implications for nuclear localization of Dicer was the reported Dicer-dependent turnover of intergenic transcripts from the human beta-globin gene cluster (Haussecker and Proudfoot, 2005). However, this study showed mostly correlation of abundance of nuclear transcripts. Nuclear Dicer processing was also implicated by several other studies (Flemr et al., 2013; Neve et al., 2016; Valen et al., 2011; White et al., 2014). In terms of function, nuclear Dicer was thought to be involved in nuclear dsRNA processing (?) (White et al., 2014), selection of alternative polyadenylation sites (Neve et al., 2016) or rRNA processing (Liang and Crooke, 2011). Several studies documented Dicer nuclear localization by microscopy. Dicer was detected in cultured mammalian cells with several different antibodies in the chromatin where it resided in rDNA clusters on acrocentric human chromosomes (Sinkkonen et al., 2010). Finer mapping using chromatin immunoprecipitation suggested that Dicer localizes in the proximity of the rRNA transcribed region (Sinkkonen et al., 2010). However, this study failed to reveal any functional significance of Dicer localization and it is not clear if the localization is related to the later reported role of Dicer in pre-rRNA processing (Liang and Crooke, 2011) or to rDNA-derived small RNAs (Wei et al., 2013).

Furthermore, localization of Dicer to rDNA is distinct from the nuclear localization of Dicer detected by fluorescence correlation/cross-correlation spectroscopy (FCS/ FCCS) (Ohrt et al., 2012), since FCS/ FCCS can detect diffusing and not rDNA chromatin-bound Dicer. FCS/FCCS identified Dicer in the nucleus in HeLa cells and suggested that nuclear Dicer is alone while the cytoplasmic Dicer exists in a large complex with AGO2 (presumably RLC) (Ohrt et al., 2012). This would imply that while Dicer could process nuclear 
substrates, they would not be loaded on AGO proteins in the nucleus. However, a later study suggested that Dicer, TARBP2, AGO2 and GW182 associate into a large complex in the nucleus although, consistently with FCS/FCCS data, loading of nuclear small RNA duplexes was not detected (Gagnon et al., 2014a). Regarding the nuclear localization mechanism of Dicer, it does not employ a canonical nuclear localization signal (NLS). A pyruvate kinase fusion system suggested that dsRBP of Dicer could function as an NLS similarly to ADAR dsRBD (Doyle et al., 2013). However, this study did not prove nuclear localization of full-length Dicer under physiological conditions. Interestingly, an additional report implied phosphorylation of Dicer in nuclear localization in nematodes, humans and mice (Drake et al., 2014). Remarkably, one of the two reported phosphorylation sites for ERK was in the dsRBD, providing a hypothetical link to analysis of the study implying dsRBD in nuclear localization of Dicer. Yet, as mentioned above, EGFP tagging of Dicer in mice does not support nuclear localization of Dicer (Much et al., 2016). Taken together, nuclear localization/function of Dicer is still poorly understood and further research is needed to build a more coherent picture from the contradictory observations.

\section{Nuclear AG01-4}

A similarly unclear situation exists for nuclear AGO1-4 proteins. AGO1-4 proteins were observed in the nucleus under different circumstances including immunofluorescent staining, such as, for example (Ahlenstiel et al., 2012; Allo et al., 2014; Aporntewan et al., 2011; Bai et al., 2014; Berezhna et al., 2006; Gagnon et al., 2014a; Huang et al., 2013a; Jang et al., 2012; Janowski et al., 2006; Kim et al., 2012; Kim et al., 2006; Liang and Crooke, 2011; Nishi et al., 2013; Ohrt et al., 2008; Ohrt et al., 2012; Robb et al., 2005; Rudel et al., 2008; Sharma et al., 2016; Tan et al., 2009a). Notably, one should be cautious about nuclear localization detected by antibodies and cellular fractionation in the absence of appropriate controls. While antibody cross-reactivity often cannot be excluded, biochemical fractionations suffer from impurities and endoplasmic reticulum contamination is frequently not examined. In any case, if there would be any consensus about nuclear AGO localization, it seems that a small fraction of AGO proteins is indeed in the nucleus and can engage complementary RNAs (Berezhna et al., 2006; Gagnon et al., 2014b; Ohrt et al., 2008; Robb et al., 2005). The mechanism of nuclear import of AGO proteins is unclear. AGO proteins do not carry a canonical NLS. It has been proposed that AGO proteins could be imported into the nucleus by GW182 (Nishi et al., 2013) or via Importin 8 (Weinmann et al., 2009).

The next section reviews effects of small RNA mechanisms in the nucleus, starting with indirect ones.

\section{Indirect effects of miRNAs on chromatin}

Studies of miRNA targets suggest that 10 to $30 \%$ of human genes are potential miRNA targets (John et al., 2004; Lewis et al., 2003). Also, experiments with delivering miRNAs into different cell types suggest that individual miRNAs can down-regulate a large number of genes (Lim et al., 2005). Thus, it is not surprising that many genes regulating chromatin structure are directly or indirectly regulated by miRNAs. One of the recent examples of 
such a connection is the regulation of DNA methylation in murine embryonic stem cells (ESCs). Phenotype analysis of Dicer ${ }^{-/}$cells revealed that the loss of Dicer in ES cells leads to defects in differentiation and it may (Kanellopoulou et al., 2005) or may not (Murchison et al., 2005) lead to aberrant changes in centromeric chromatin. It has been speculated that Dicer functions in a pathway similar to that of Schizosaccharomyces pombe (Kanellopoulou et al., 2005). This interpretation was consistent with previous analysis of chicken-human hybrid DT40 cell line lacking Dicer, where defects in heterochromatin were also observed (Fukagawa et al., 2004). However, cloning of small RNAs from WT and Dicer ${ }^{-/}$ES cells suggests that ES cells do not naturally produce endogenous siRNAs and that Dicer exclusively produces miRNAs (Calabrese et al., 2007).

Detailed analysis of the transcriptome of murine Dicer-/ ES cells (Sinkkonen et al., 2008) correlated changes of gene expression with the presence of binding sites for AAGUGC-seeded miRNAs (miR-290 cluster and other miRNAs), which were previously found in human and murine ES cells (Houbaviy et al., 2005; Suh et al., 2004). The loss of Dicer and miRNAs resulted in down-regulation of de novo DNA methyltransferases and defects in de novo DNA methylation during differentiation. This defect could be rescued by over-expressing de novo DNA methyltransferases or by transfection of the miR-290 cluster miRNAs (Sinkkonen et al., 2008). These data were complemented by the study of Benetti et al., who showed that the loss of Dicer leads to decreased DNA methylation, concomitant with increased telomere recombination and telomere elongation (Benetti et al., 2008).

Regulation of de novo DNA methyltransferases by miRNAs is likely much more complex than described above because other miRNAs were also implicated in their direct regulation in other cell types (Duursma et al., 2008; Fabbri et al., 2007). Importantly, the genetic background or culturing conditions can also influence epigenetic changes in studied cells, which might explain why a third study of Dicer-deficient ESCs observed normal DNA methylation dynamics (Ip et al., 2012).

In any case, it is very likely that miRNAs play a similar role in other aspects of chromatin formation. Considering that up to $60 \%$ of the genes are possibly regulated by miRNAs, data from experiments which directly or indirectly affect the miRNA pathway (including siRNA off-targeting), should be handled with open mind and great caution.

\section{Post-transcriptional regulations by small RNAs in the nucleus - nuclear RNAi}

In mammalian cells, Robb et al. showed that nuclear RNAs can be targeted by RNAi (Robb et al., 2005). In addition they also provided biochemical data showing that AGO1 and AGO2 localize into the nuclear RISC (Robb et al., 2005). While these data did not make a conclusive evidence as contamination of the nuclear fraction with AGO proteins associated with outer nuclear envelope could not be excluded, nuclear localization of AGOs was later backed up by other data (Berezhna et al., 2006; Gagnon et al., 2014b; Ohrt et al., 2008). Berezhna et al. showed that siRNAs accumulate in the nucleus in a cognate mRNA dependent manner (Berezhna et al., 2006). Ohrt et al. reported that siRNAs against firefly luciferase microinjected into HeLa cells enter nucleus but are actively excluded from non-nucleolar space in Exportin-5 dependent manner (Ohrt et al., 2006). 
Taken together, loaded AGO2 seems to be able to engage nuclear RNAs and, in case of perfect complementarity, it can cleave its targets. How nuclear RNAi incorporates nuclear and cytoplasmic small RNA precursors and how it is working under physiological conditions on perfectly complementary and partially complementary targets remains largely unknown.

\section{Transcriptional regulations (stimulation/repression) by exo-siRNAs}

In plants and fungi, RNA silencing mechanisms also mediate transcriptional silencing. Similar transcriptional silencing phenomena were intensely searched also in mammals. The first two reports of transcriptional silencing in mammals were published in 2004 when two groups reported siRNA-mediated transcriptional silencing coupled with DNA methylation (Kawasaki and Taira, 2004; Morris et al., 2004) and laid problematic foundations of transcriptional silencing research in mammals. The reason is that reproducibility of both reports was quickly questioned and one of them was later forced retracted, formally because "a proper data notebook is not available as evidence to support our findings, which constitutes non-adherence to ethical standards in scientific research. In accordance with the recommendations from the National Institute of Advanced Industrial Science and Technology, K.T. therefore wishes to retract this paper." (Taira, 2006). While the second report has not been retracted, DNA methylation has been doubted as a key silencing effect (Ting et al., 2005). Furthermore, the report did not analyse induction of DNA methylation by informative bisulfite sequencing but relied on suboptimal methylation-sensitive restriction digest. Another troubling aspect of the second report is a technically impossible transcriptional silencing experiment shown in Fig. 1B, which raises a question how careful was the peer reviewing process. In any case, transcriptional misregulation by exogenous oligonucleotides complementary to promoter sequences has been reported by different laboratories for different promoters in different cells arguing that some complementarity-based transcriptional regulation by small RNAs functions in mammalian cells. Importantly, the underlying mechanism was not conclusively revealed after a decade and is still a matter of debates.

The siRNA-induced transcriptional silencing involves changes in the chromatin structure such as loss of "active" histone modifications (H3K4 methylation, histone acetylation) (Janowski et al., 2006; Morris et al., 2004), appearance of "inactive" histone modifications (H3K9 and H3K27 methylation) (Castanotto et al., 2005; Janowski et al., 2006; Jiang et al., 2012; Kim et al., 2006; Kim et al., 2007; Weinberg et al., 2006), and occasionally DNA methylation (Morris et al., 2004). These are all common features of transcriptional repression and could be either directly induced by siRNA-containing complexes or they be a consequence of transcriptional silencing. DNA methylation is apparently a secondary effect (Ting et al., 2005) although a systematic analysis revealed a group of gene promoters whose methylation was dependent on Dicer (Ting et al., 2008).

Small RNAs used for silencing were either "classical" synthesized siRNAs (agRNAs) (Ahlenstiel et al., 2012; Castanotto et al., 2005; Hawkins et al., 2009; Janowski et al., 2005a; Jiang et al., 2012; Kim et al., 2007; Morris et al., 2004; Napoli et al., 2009; Ting et al., 2005) or shRNAs expressed from a plasmid (Castanotto et al., 2005; Kim et al., 2007). Importantly, transcriptional silencing could be induced by a variety of antisense oligomers 
targeting promoter sequences such as single-stranded antigene (ag) peptide nucleic acid (PNA) (Janowski et al., 2005b), PNA-peptide conjugates (Hu and Corey, 2007), locked nucleic acid (LNA) (Beane et al., 2007) or duplex RNA (siRNA) oligos (Janowski et al., 2005a). These results represent a remarkably comprehensive set of data concerning inhibition of human progesterone receptor A (hPR-A) and B (hPR-B) isoforms. Despite all approaches achieved inhibition of gene expression, these silencing oligonucleotides have radically different properties and it is questionable whether they would all operate loaded on an AGO protein in a RISC-like complex.

Furthermore, studies of oligonucleotides targeting promoter sequences revealed that some oligonucleotides have a positive effect on transcription (Janowski et al., 2007; Li et al., 2006). The activating effect of small RNAs also appeared later in other reports (Hu et al., 2012; Wang et al., 2015a; Zhang et al., 2014). "Scanning" a promoter with oligonucleotides revealed the existence of sites whose targeting results in transcriptional repression as well as sites whose targeting promotes expression (Janowski et al., 2005a; Janowski et al., 2007). According to these data, a shift by several nucleotides could have an opposite effect on gene expression that would correlate with changes in histone modifications. These data would imply existence of a still-unknown RISC-like nuclear complex acting as a switch or siRNA strand-selection onto a single RISC-like complex, where the opposing effects would stem from targeting sense and antisense RNAs in the locus. Alternatively, the observed silencing stems from the oligonucleotide binding and is not mechanistically involving AGO proteins.

To date, the active agent of the silencing has not been conclusively identified and critically assessed. It still remains a question whether there is a dedicated transcriptional silencing machinery in mammalian cells involving AGO proteins and some binding partners as proposed by some reports (Cho et al., 2014; Hawkins et al., 2009; Hu et al., 2012; Janowski et al., 2006; Kim et al., 2006; Suzuki et al., 2008), which are partially contradicting themselves and are not supported by proteomic analysis of AGO complexes (Hauptmann et al., 2015; Hock et al., 2007; Meister et al., 2005), or various artificial disturbances of lncRNAs generate the observed effects.

\section{Transcriptional regulations (stimulation/repression) by miRNAs}

A peculiar phenomenon of miRNA-associated transcriptional activation was reported from cultured mammalian cells for the E-cadherin and cold-shock domain-containing protein $\mathrm{C} 2$ (CSDC2) promoters and the miR-373 (Place et al., 2008). The initial observation leading to discovery of this phenomenon was that transfection of siRNAs homologous to E-cadherin, $\mathrm{p} 21 \mathrm{WAF} 1 / \mathrm{CIP} 1$, and VEGF promoters lead to unexpected transcriptional activation (Li et al., 2006). Subsequent sequence analysis of the E-cadherin promoter revealed high complementarity between the miR-373 and the sequence at position -645 relative to the transcription start site (Place et al., 2008). Delivery of miR-373, pre-miR373 and a synthetic siRNA sequence targeting -640 position could stimulate E-cadherin expression by 5-7-fold in PC-3 cells. Interestingly, intact miRNA pathway was required for the E-cadherin stimulation as partial down-regulation of Dicer protein by morpholino oligonucleotides abolished the stimulatory effect of pre-miR-373. Since then, several other reports of 
miRNA-mediated transcriptional silencing appeared, including transcriptional inhibition of HOXD4 expression by miRNA-10a (Tan et al., 2009b), miR-320-mediated transcriptional silencing of POLR3D (Kim et al., 2008), and others (Adilakshmi et al., 2012; Benhamed et al., 2012; Kim et al., 2011)

It remains an open question whether effects of exogenous siRNAs represent the same molecular mechanism as those attributed to nuclear activities of miRNAs. It would be supported by non-cleaving AGO1 implicated in transcriptional regulation (Huang et al., 2013a; Janowski et al., 2006; Kim et al., 2006) and transcriptional silencing by miRNA mimics targeting gene promoters (Younger and Corey, 2011). In terms of the possible miRNA-mediated nuclear silencing, it was reported that POLR3D silencing involves miRNA-mediated promoter association with a complex including AGO1 and EZH2 (H3K27 histone methyltransferase) (Kim et al., 2008). It was also suggested that AGO1 interacts with polymerase II (Huang et al., 2013a; Kim et al., 2006). At the same time, others implicated GW182 as the factor important for nuclear localization and function of nuclear AGO proteins (Nishi et al., 2013; Nishi et al., 2015). However, the mechanistic link between AGO-GW182 and histone modifications still remains elusive.

\section{7nt RNAs - mediated regulation of endothelial nitric oxide synthase gene}

This phenomenon has been observed in endothelial nitric oxide synthase (eNOS) where a $27 \mathrm{nt}$ repeat polymorphism in intron 4 was a source of predominantly nuclear $27 \mathrm{nt}$ small RNAs, which could be either a novel class of small RNAs, or atypical miRNAs (Zhang et al., 2008b). In any case, these $27 \mathrm{nt}$ RNAs were implicated in eNOS suppression by altering histone acetylation and DNA methylation in regions adjacent to the $27 \mathrm{nt}$ repeat element and core promoter (Zhang et al., 2008a). Whether this phenomenon is related to other ones described here remains unclear.

\section{Regulation of splicing}

In addition to transcriptional and post-transcriptional silencing, one of the reported effects of small RNAs transfected into mammalian cells was also an impact on alternative splicing (Allo et al., 2009). A mechanism was proposed, which involves AGO1 recruitment to transcriptional enhancers (Allo et al., 2014), while other reports implicated AGO2 (Liu et al., 2012; Liu et al., 2015) or both (Ameyar-Zazoua et al., 2012).

\section{Small RNAs associated with DNA repair}

The last nuclear phenomenon associated with small RNAs is their emergence upon DNA damage. It was reported that DICER and DROSHA-dependent small RNAs emerge as DNA-damage response and are functionally associated with it through the MRE11 complex (Francia et al., 2012). In addition, knock-down of Dicer or AGO2 in human cells reduced double-stranded break repair (Wei et al., 2012). It was proposed that small RNAs emerging from DNA -damage loci may function as guide molecules directing chromatin modifications or the recruitment of protein complexes to facilitate repair (Francia et al., 
2012; Wei et al., 2012). What is somewhat confusing in DNA-repair associated small RNAs is the role of miRNA-specific factors Drosha (Francia et al., 2012) or DGCR8 (Swahari et al., 2016).

Despite the heterogeneity of the nuclear effects and many unknowns, some common themes emerged, allowing for formulating testable hypotheses that could be critically evaluated. First, nuclear effects can be mediated by small RNAs provided in trans. Second, small RNAs recruit AGO proteins in a sequence-specific manner, most likely recognizing a local transcript (perhaps an ncRNA). Third, the effect involves a change in the chromatin structure. Thus, by carefully examining essential exogenous siRNA properties in previously reported nuclear effects, one should be able to demonstrate that the silencing phenomenon truly involves an AGO-loaded small RNA engaging another nuclear RNA and whether the effect requires the "slicer" activity. Detailed examination of the seed sequence would also discern between specific nuclear effects and off-targeting. Furthermore, should the effect involve small RNA loaded AGO protein, the kinetics of the phenomenon should be in agreement with known RISC kinetics discussed above. Finally, if the aforementioned phenomena rely on localized recruitment of AGO-loaded small RNAs, one should be able to mimic those effects by tethering AGO proteins through sequence-specific DNA binding modules such as those employed by TALEN or CRISPR nucleases. These research directions should be combined with validated antibodies for chromatin immunoprecipitation and immunofluorescence (or epitope knock-in into candidate genes), more extensive use of mutants defective in RNA silencing, detailed quantitative analysis of cellular fractionation and identifications of interacting partner, studies of putative nuclear import and export signals of Dicer and AGO proteins, and advanced imaging techniques.

\section{Other dsRNA-associated mechanisms I - dsRNA sensing in the interferon pathway}

Long dsRNA is not a usual RNA molecule in eukaryotic cells while RNA viruses produce dsRNA during replication. A common mechanism repressing viruses in non-vertebrate species is RNA silencing (Wang et al., 2006; Wilkins et al., 2005). However, response to foreign long dsRNA in mammals is much more complex and involves a set of sequence-independent sensors triggering expression of a defined set of genes known as interferon-stimulated genes (ISGs). The interferon pathway is the most ubiquitous sequence-independent pathway induced by dsRNA in mammalian cells (reviewed in detail in de Veer et al., 2005). Among the relevant sensors recognizing cytoplasmic dsRNA are protein kinase R (PKR), the helicase RIG-I, MDA5, 2', 5' -oligoadenylate synthetase (2',5'-OAS), or Toll-like receptors (TLR3, 7, 8) (reviewed in Gantier and Williams, 2007; Sadler and Williams, 2007). Notably, there are also dsRNA-independent mechanisms that can activate interferons in mammalian cells. Altogether, different stimuli are being sensed and converge on activation of overlapping but distinct sets of ISGs (Geiss et al., 2001). The situation is even more convoluted by cellular diversity as some cell types, particularly immune cells, can elicit the interferon response by additional, cell-type-specific pathways (reviewed in Schlee and Hartmann, 2010). 


\section{PKR}

PKR is the oldest known mammalian dsRNA sensing protein. A pioneering work by Hunter et al. showed that different types of dsRNA can block translation in reticulocyte lysates (Hunter et al., 1975). Analysis of the phenomenon identified PKR that is activated upon binding to dsRNA and blocks translation by phosphorylating the alpha subunit of eukaryotic initiation factor 2 (eIF-2 $\alpha$ ) (Meurs et al., 1990). Activation of PKR also includes activation of the $\mathrm{NF} \kappa \mathrm{B}$ transcription factor and a large number of interferon-stimulated genes (ISGs) (Geiss et al., 2001). PKR response to viral dsRNA can be coordinated with other dsRNA sensors, such as RIG-I and MDA5 (Sen et al., 2011). PKR can also respond to endogenous RNAs in unique physiological regulations (Bevilacqua et al., 1998; Bommer et al., 2002). However, endogenously expressed long dsRNA does not necessarily induce canonical PKR response with interferon activation, although PKR binding to dsRNA and restricted translational repression can be observed (Nejepinska et al., 2012; Nejepinska et al., 2014). It was believed that dsRNA $<30$-bp in length does not induce PKR. However, Marques et al. reported that, siRNAs can bind and activate PKR in vitro regardless of siRNA termini (Marques et al., 2006) arguing against the long-established 30-bp length as the minimal size-limit for PKR activation. There are also other data indicating sensitivity of PKR to dsRNA motifs shorter than 30-bp (Puthenveetil et al., 2006; Reynolds et al., 2006; Zheng and Bevilacqua, 2004).

\section{RIG-I-like receptors (RIG-I, MDA5, LGP2)}

Mammalian somatic cells can respond to dsRNA in a sequence-independent manner.. In addition to PKR, several other proteins recognizing dsRNA are integrated to the interferon response, including helicases RIG-I (retinoic-acid-inducible gene-I, also known as DDX58), MDA5 (IFIH1), and LGP2 (DHX58), which sense cytoplasmic dsRNA and activate interferon expression.

RIG-I is a cytoplasmic sensor differentiating between endogenous and foreign RNAs structures. In particular, RIG-I is activated by blunt-ended dsRNAs with or without a 5'-triphosphate, by single-stranded RNA marked by a 5'- triphosphate, and by polyuridine sequences. RIG-I domains organize into a ring around dsRNA, capping one end, while contacting both strands; the structure is consistent with dsRNA translocation without unwinding and cooperative binding to RNA (Jiang et al., 2011a; Jiang et al., 2011b). Like RIG-I and LGP2, MDA5 preferentially binds dsRNA with blunt ends (Li et al., 2009a). RIG-I, MDA5, and LGP2 exhibit differences in recognizing specific RNA structures and different types of viruses providing a broader range of coordinated sensitivity do different potential threats (Kato et al., 2006; Li et al., 2009b; McCartney et al., 2008; Sen et al., 2011; Slater et al., 2010; Wu et al., 2015b). Interestingly, RIG-I can become activated also with siRNAs lacking 2-nt 3' overhangs (Marques et al., 2006). These data imply that 2-nt 3' overhangs generated by Dicer are the structural basis for discriminating between Dicer products and other short dsRNA. Roles of MDA5 and LGP2 in siRNA-mediated interferon response remains to be addressed. Furthermore, recognition 5' triphosphate RNA ends RIG-I (Hornung et al., 2006; Pichlmair et al., 2006) highlights importance of appropriate 
processing of 5' termini of RNAs produced by phage polymerases when such RNAs are used in mammalian cells.

It is not clear how PKR and RIG-I pathways are integrated. RIG-I binds siRNAs (with or without 2-nt 3' overhangs) in vitro and it shows greater unwinding of blunt-ended siRNAs. Unwinding is then translated into the interferon activation mediated via IRF-3.

\section{Toll-like Receptor 3 (TLR3)}

TLR3 is a member of the Toll-like receptor (TLR) family and functions as a sensor of extracellular, intracellular and viral dsRNAs (Amarante et al., 2011; Seo et al., 2013; Wang et al., 2015b; Wu et al., 2015b; Yang et al., 2006b). TLR3 has distinct or complementary roles to RIG-I and related helicases in sensing foreign molecules and activating downstream responses (Livengood et al., 2007; McCartney et al., 2009; Slater et al., 2010; Wu et al., 2015b).

\section{Oligoadenylate Synthetase (OAS)}

Interferon and dsRNA also activate $2^{\prime}, 5^{\prime}$-oligoadenylate synthetase $\left(2^{\prime}, 5^{\prime}-\mathrm{OAS}\right)$ that produces 2',5' oligoadenylates with 5'-terminal triphosphate residues that subsequently induce activation of RNAse L; a protein responsible for general RNA degradation (de Veer et al., 2005).

\section{TARBP2 and PACT}

Interactions between RNAi, miRNA, and interferon response are poorly understood. There are two clear mechanistic connections between these two pathways. First, TARBP2 and PACT, two dsRNA binding proteins, which were mentioned earlier as Dicer-interacting proteins, interact also with PKR. Notably, while TARBP2 inhibits PKR (Cosentino et al., 1995; Park et al., 1994), PACT has the opposite role (Patel and Sen, 1998). While cytoplasmic long dsRNA in somatic cells apparently triggers the interferon response, it is not clear if the same dsRNA is also routed into the RNAi pathways. Experiments in oocytes and undifferentiated embryonic stem cells (Stein et al., 2005; Yang et al., 2001) suggest that RNAi dominates response to cytoplasmic long dsRNA in the absence of a strong interferon response and that the interferon pathway dominates when its relevant components are present. On the other hand, this view may be too simplistic as it does not explain the lack of both, RNAi and interferon response, in somatic cells expressing long dsRNA (Nejepinska et al., 2012; Nejepinska et al., 2014). In any case, understanding the role of TARBP2 and PACT isoforms in routing long dsRNA into RNAi and interferon pathways requires further studies.

There is a clear evolutionary connection between RNAi and interferon response. The above-mentioned mammalian RNA helicases RIG-I, LGP2 and MDA5 are the closest homologs of helicases involved in processing of long dsRNA during RNAi in C. elegans. Notably, RIG-I is an established component of the interferon response to long dsRNA (Yoneyama et al., 2004). This suggests that the interferon response, which has a common 
trigger and evolved after the RNAi pathway, adopted several components from the latter pathway. It remains to be determined whether these and other components of RNAi lost their function in RNAi entirely or mediate some form of a cross-talk between RNAi and interferon response.

Finally, there is also a complex relationship between miRNA and interferon pathways (Ingle et al., 2015; Ostermann et al., 2012; Shapiro et al., 2014; Xu et al., 2011). One connection is exemplified by viral miRNAs, which viruses use to regulate the host response, in particular factors of the interferon pathway (Ostermann et al., 2012) or other cellular signalling (Xu et al., 2011). However endogenous cellular miRNAs may also act to suppress the interferon response factors, such as the case mir-485, which has a dual role in targeting RIG-I as well as the influenza virus H5N1 (Ingle et al., 2015).

\section{Other dsRNA-associated mechanisms II - Adenosine deamination}

A-to-I editing is a covalent RNA modification system of broad significance (reviewed in Nishikura, 2016). It is mediated by adenosine deaminases acting on RNA (ADARs), enzymes that carry two or three dsRBD and recognize both inter- and intramolecular dsRNAs longer than 20-30 bp (Nishikura et al., 1991). ADARs convert adenosines to inosines, which base pair with cytosines, which are interpreted as guanosines during translation. Thus, RNA editing affects coding potential, fidelity of RNA replication reverse transcription, or formation/stability of RNA secondary structures where a change of a single base in a sequence may result either in dsRNA destabilization (inosine-uridine pair) or stabilization (inosine-cytidine pair) (Nishikura, 2010). Such transition in the local and global stability of dsRNA structure can influence further processing of dsRNA, such as the selection of the effective miRNA strand (Bartel, 2004; Meister and Tuschl, 2004).

Mammals (and vertebrates in general) have three ADAR genes (reviewed in Nishikura, 2016) (Fig. 3). Two encode proteins carrying deaminase activity: ADAR1, which is interferon-inducible, and ADAR2, which is constitutively expressed. ADAR3 is mostly expressed in the brain but its editing activity has not been shown yet. The specificity of the ADAR1 and ADAR2 deaminases ranges from highly site-selective to non-selective, dependent on the duplex structure of the substrate RNA.

The complete ADAR structure has not been solved yet but structure of several domains is known - the $\mathrm{Z}$ alpha domain of the human editing enzyme ADAR1 (Schwartz et al., 1999) and dsRBDs of ADAR2 (Stefl et al., 2010). The analysis of dsRBDs provided an insight into editing of a specific substrate and revealed that dsRBDs of ADAR not only recognize the shape but also the sequence of the dsRNA (Stefl et al., 2010). The unexpected direct readout of the RNA primary sequence by dsRBDs is achieved via the minor groove of the dsRNA and this recognition is critical for both editing and binding affinity of edited RNA (Stefl et al., 2010). It was also shown that ADAR2 forms dimers in vivo and that dsRBDs are necessary and sufficient for dimerization of the enzyme (Poulsen et al., 2006).

ADARs exhibit complex regulation of localization. For example, it was shown that mouse ADAR1 isoforms are differentially localized in cellular compartments and that their 


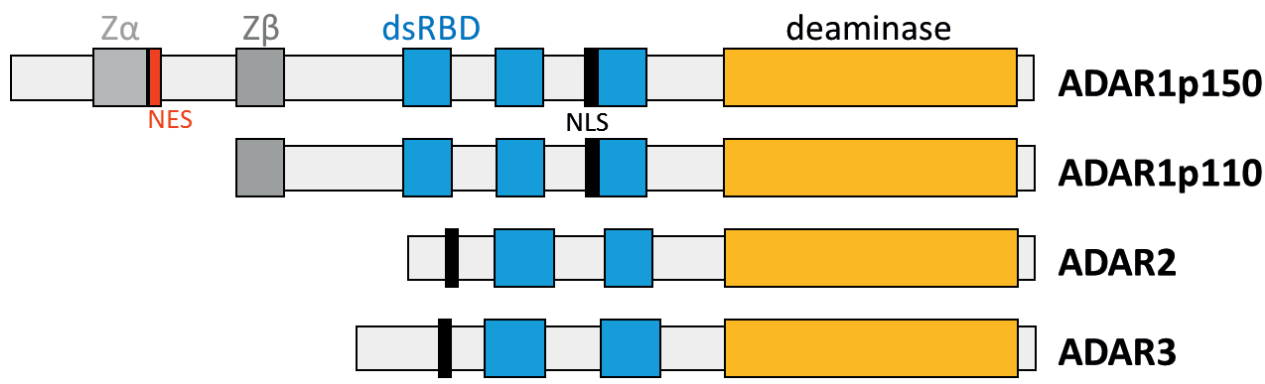

Figure 3 Domain composition of mammalian ADAR proteins

NES, nuclear export signal, NLS, nuclear localization signal; dsRBD, dsRNA binding domain.

localization is controlled by several independent signals, which include a nuclear localization signal (NLS), the nucleolar localization signal (NoLS), the nuclear exporter signal (NES) near the $\mathrm{N}$ terminus (Nie et al., 2004). ADAR1 interacts with TUDOR-SN nuclease (Nishikura, 2010; Scadden, 2005; Weissbach and Scadden, 2012; Yang et al., 2006a) and localizes to stress granules upon stress induction (Weissbach and Scadden, 2012) while tudor-SN degrades hyperedited dsRNA (Scadden, 2005).

RNA editing concerns a broad range of RNAs including viral and cellular RNAs. Many long perfect dsRNAs (>100 bp) undergo extensive editing with a conversion of approximately $50 \%$ of adenosines to inosines (Nishikura et al., 1991; Polson and Bass, 1994). Extensive editing (hyperediting) is linked with nuclear retention (reviewed in DeCerbo and Carmichael, 2005). On the other hand, short RNAs ( 20-30 bp) or imperfect long dsRNAs are edited selectively; usually only a few adenines at specific sites are deaminated (Lehmann and Bass, 1999). High throughput analyses revealed the extent of RNA editing of mammalian RNAs in terms of substrate diversity and frequency of editing in the transcriptome (Carmi et al., 2011; Peng et al., 2012). Edited endogenous RNAs (Dawson et al., 2004; Hundley et al., 2008; Morse et al., 2002; Salameh et al., 2015) include mRNAs, repetitive sequences (mainly Alu (Athanasiadis et al., 2004)), and miRNAs. It was predicted that more than $85 \%$ of pre-mRNAs may be edited, predominantly in the non-coding regions (Athanasiadis et al., 2004).

Several pri-miRNAs (e.g. miR-142) are known to undergo editing, which inhibits Drosha cleavage or even causes degradation of pri-miRNA by Tudor SN (Nishikura, 2010; Scadden, 2005; Yang et al., 2006a). In other cases, pri-miRNA editing does not influence Drosha activity but inhibits processing of pre-miRNA by Dicer (e.g. miR-151) (Kawahara et al., 2007a). Last but not least, RNA editing might also inhibit export of miRNAs from the nucleus (Nishikura, 2010). A systematic analysis of edited miRNAs in the human brain showed that editing of miRNAs affects several miRNAs but it is not widespread (Alon et al., 2012). A similar picture was obtained from analysis of embryonic miRNAs (Garcia-Lopez et al., 2013; Vesely et al., 2012)

One of the roles of ADARs in immunity is to prevent innate immune sensing of self-RNA (Heraud-Farlow and Walkley, 2016). ADARs also affect viral RNAs in various ways ADARs are both antiviral and proviral; the effect on virus growth and persistence depends 
upon the specific virus. (Samuel, 2011). Viruses targeted by ADARs in mammals include HIV (Clerzius et al., 2009), herpesvirus (Gandy et al., 2007), HRSV (Martinez and Melero, 2002), HCMV (Nachmani et al., 2014), VSV (Nie et al., 2007), and HDV (Wong and Lazinski, 2002).

\section{Crosstalk between RNA editing and other dsRNA pathways.}

ADARs affect other dsRNA pathways in several ways. In RNA silencing, ADARs can compete with RNAi for dsRNA substrates (including siRNAs). The ADAR1 isoform (ADAR1p150) strongly binds siRNA and reduces thus the availability of dsRNA for RNAi, resulting in less efficient RNAi in normal cells compared to Adar $1^{-/-}$cells (Yang et al., 2005). Interestingly, injection of high doses of siRNAs enhances ADAR1 expression, suggesting a role of ADAR1 in a cellular feedback mechanism in response to siRNA (Hong et al., 2005).

Editing affects base pairing quality of dsRNA substrates as well as target recognition since a single nucleotide mismatch between siRNA and target mRNA can reduce RNAi efficacy (Scadden and Smith, 2001) or modify target specificity, especially when occurring in the seed sequence (Kawahara et al., 2007b). MiRNAs would be affected in a similar way. A moderate deamination (one I-U pair per siRNA) does not prevent Dicer processing to siRNAs (Zamore et al., 2000$)$ but, hyperediting ( $\sim 50 \%$ of deaminated adenosines) can make dsRNA resistant to Dicer processing (Scadden and Smith, 2001).

Thus, ADARs are factors conferring to formation of RNAi resistance (Hong et al., 2005), which may be one of the viral strategies to avoid being targeted through a dsRNA-responding pathway (Zheng et al., 2005). ADARs influence the innate immunity either indirectly by preventing sensing of self-RNA (Heraud-Farlow and Walkley, 2016) or by interacting with innate immunity factors, such as PKR (Clerzius et al., 2009). The immunosuppressive role of ADAR1 could explain the phenotype of the Aicardi-Goutieres syndrome (AGS, OMIM\# 225750), an autoimmune disorder caused by ADAR1 mutations (Rice et al., 2012). It has been proposed that in the absence of ADAR1, accumulation of cytoplasmic dsRNA may provoke interferon signalling and cause upregulation of interferon-stimulated genes, which is observed in AGS (Rice et al., 2012).

\section{Summary}

In mammals (Fig. 4), the miRNA pathway seems to be the dominant small RNA pathway in the soma while the existence and functionality of endogenous RNAi remains unclear. The only cell type with well documented robust and mechanistically explained endo-RNAi is the mouse oocyte. Somatic cells typically respond to long dsRNA with a sequence-independent interferon response, which is employing multiple dsRNA sensors, which trigger a complex interferon response. 


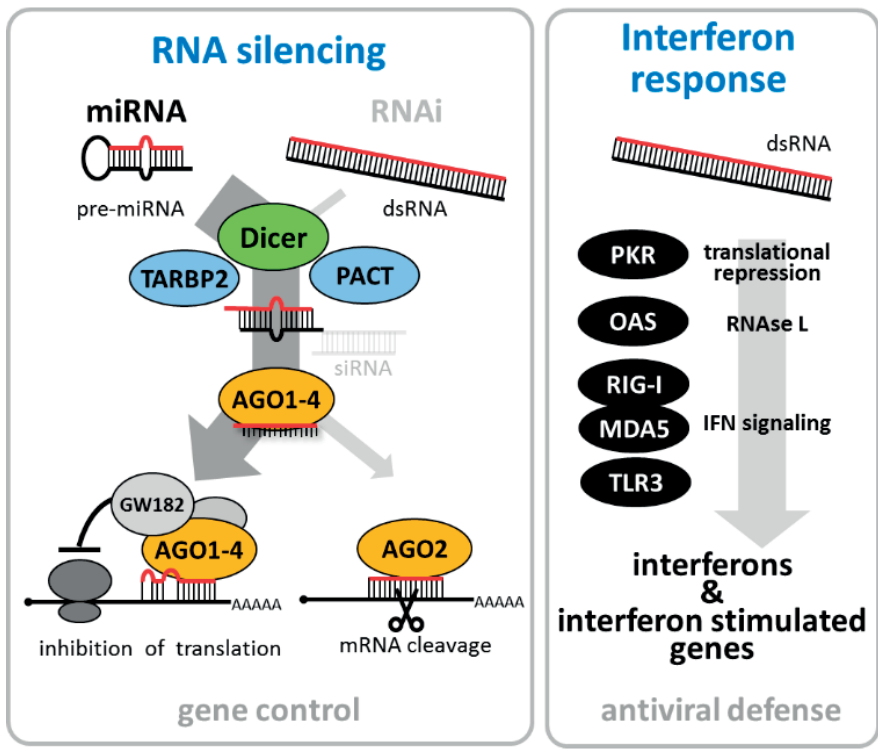

Figure 4 Summary of mammalian RNA silencing and dsRNA response pathways. On the right are schematically depicted dsRNA sensors in the sequence-independent interferon response.

\section{Acknowledgement}

I would like to thank my colleagues Jan Paces, Miloslav Nic, and Tomas Novotny for help with collecting literature for the review. The review content was produced under a contract OC/EFSA/GMO/2015/01-CT 01 with European Food Safety Authority (EFSA); the opinions expressed are those of the contractor only and do not represent EFSA's official position. Publication of the review was funded by LO1220 and LM2015063 by the Ministry of Education, Youth and Sports.

\section{References}

Adilakshmi, T., Sudol, I., and Tapinos, N. (2012). Combinatorial Action of miRNAs Regulates Transcriptional and Post-Transcriptional Gene Silencing following in vivo PNS Injury. Plos One 7, e39674-e39674.

Ahlenstiel, C.L., Lim, H.G.W., Cooper, D.A., Ishida, T., Kelleher, A.D., and Suzuki, K. (2012). Direct evidence of nuclear Argonaute distribution during transcriptional silencing links the actin cytoskeleton to nuclear RNAi machinery in human cells. Nucleic Acids Research 40, 1579-1595.

Allo, M., Agirre, E., Bessonov, S., Bertucci, P., Acuna, L.G., Buggiano, V., Bellora, N., Singh, B., Petrillo, E., Blaustein, M., et al. (2014). Argonaute-1 binds transcriptional enhancers and controls constitutive and alternative splicing in human cells. Proc Natl Acad Sci U S A 111, $15622-15629$. 
Allo, M., Buggiano, V., Fededa, J.P., Petrillo, E., Schor, I., de la Mata, M., Agirre, E., Plass, M., Eyras, E., Elela, S.A., et al. (2009). Control of alternative splicing through siRNA-mediated transcriptional gene silencing. Nature Structural \& Molecular Biology 16, 717-724.

Alon, S., Mor, E., Vigneault, F., Church, G.M., Locatelli, F., Galeano, F., Gallo, A., Shomron, N., and Eisenberg, E. (2012). Systematic identification of edited microRNAs in the human brain. Genome Research 22, 1533-1540.

Amarante, M.K., Oda, J.M.M., Reiche, E.M.V., Morimoto, H.K., Aoki, M.N., and Watanabe, M.A.E. (2011). Human endogenous RNAs: Implications for the immunomodulation of Toll-like receptor 3. Experimental and Therapeutic Medicine 2, 925-929.

Ameyar-Zazoua, M., Rachez, C., Souidi, M., Robin, P., Fritsch, L., Young, R., Morozova, N., Fenouil, R., Descostes, N., Andrau, J.-C., et al. (2012). Argonaute proteins couple chromatin silencing to alternative splicing. Nature Structural \& Molecular Biology 19, 998-U946.

Aporntewan, C., Phokaew, C., Piriyapongsa, J., Ngamphiw, C., Ittiwut, C., Tongsima, S., and Mutirangura, A. (2011). Hypomethylation of Intragenic LINE-1 Represses Transcription in Cancer Cells through AGO2. Plos One 6, e17934-e17934.

Arroyo, J.D., Chevillet, J.R., Kroh, E.M., Ruf, I.K., Pritchard, C.C., Gibson, D.F., Mitchell, P.S., Bennett, C.F., Pogosova-Agadjanyan, E.L., Stirewalt, D.L., et al. (2011). Argonaute2 complexes carry a population of circulating microRNAs independent of vesicles in human plasma. Proc Natl Acad Sci U S A 108, 5003-5008.

Athanasiadis, A., Rich, A., and Maas, S. (2004). Widespread A-to-I RNA editing of Alu-containing mRNAs in the human transcriptome. Plos Biology 2, e391.

Babiarz, J.E., Ruby, J.G., Wang, Y.M., Bartel, D.P., and Blelloch, R. (2008). Mouse ES cells express endogenous shRNAs, siRNAs, and other Microprocessor-independent, Dicer-dependent small RNAs. Genes \& Development 22, 2773-2785.

Baglio, S.R., Rooijers, K., Koppers-Lalic, D., Verweij, F.J., Pérez Lanzón, M., Zini, N., Naaijkens, B., Perut, F., Niessen, H.W.M., Baldini, N., et al. (2015). Human bone marrow- and adipose-mesenchymal stem cells secrete exosomes enriched in distinctive miRNA and tRNA species. Stem Cell Research and Therapy 6.

Bai, B.Y., Liu, H., and Laiho, M. (2014). Small RNA expression and deep sequencing analyses of the nucleolus reveal the presence of nucleolus-associated microRNAs. FEBS Open Bio 4, 441-449.

Bartel, D.P. (2004). MicroRNAs: genomics, biogenesis, mechanism, and function. Cell 116, 281-297.

Beane, R.L., Ram, R., Gabillet, S., Arar, K., Monia, B.P., and Corey, D.R. (2007). Inhibiting gene expression with locked nucleic acids (LNAs) that target chromosomal DNA. Biochemistry 46, 7572-7580.

Bellingham, S.A., Coleman, B.M., and Hill, A.F. (2012). Small RNA deep sequencing reveals a distinct miRNA signature released in exosomes from prion-infected neuronal cells. Nucleic Acids Research 40, 10937-10949.

Benetti, R., Gonzalo, S., Jaco, I., Munoz, P., Gonzalez, S., Schoeftner, S., Murchison, E., Andl, T., Chen, T., Klatt, P., et al. (2008). A mammalian microRNA cluster controls DNA methylation and telomere recombination via Rbl2-dependent regulation of DNA methyltransferases. Nature Structural \& Molecular Biology 15, 268-279.

Benhamed, M., Herbig, U., Ye, T., Dejean, A., and Bischof, O. (2012). Senescence is an endogenous trigger for microRNA-directed transcriptional gene silencing in human cells. Nature Cell Biology 14, 266-+. 
Bennasser, Y., Le, S.Y., Benkirane, M., and Jeang, K.T. (2005). Evidence that HIV-1 encodes an siRNA and a suppressor of RNA silencing. Immunity 22, 607-619.

Berezhna, S.Y., Supekova, L., Supek, F., Schultz, P.G., and Deniz, A.A. (2006). siRNA in human cells selectively localizes to target RNA sites. Proc Natl Acad Sci U S A 103, 7682-7687.

Bevilacqua, P.C., George, C.X., Samuel, C.E., and Cech, T.R. (1998). Binding of the protein kinase PKR to RNAs with secondary structure defects: Role of the tandem A-G mismatch and noncontiguous helixes. Biochemistry 37, 6303-6316.

Billy, E., Brondani, V., Zhang, H.D., Muller, U., and Filipowicz, W. (2001). Specific interference with gene expression induced by long, double-stranded RNA in mouse embryonal teratocarcinoma cell lines. Proc Natl Acad Sci U S A 98, 14428-14433.

Bommer, U.A., Borovjagin, A.V., Greagg, M.A., Jeffrey, I.W., Russell, P., Laing, K.G., Lee, M., and Clemens, M.J. (2002). The mRNA of the translationally controlled tumor protein P23/TCTP is a highly structured RNA, which activates the dsRNA-dependent protein kinase PKR. RNA 8 , 478-496.

Buck, A.H., Coakley, G., Simbari, F., McSorley, H.J., Quintana, J.F., Le Bihan, T., Kumar, S., Abreu-Goodger, C., Lear, M., Harcus, Y., et al. (2014). Exosomes secreted by nematode parasites transfer small RNAs to mammalian cells and modulate innate immunity. Nature Communications $5,5488-5488$.

Calabrese, J.M., Seila, A.C., Yeo, G.W., and Sharp, P.A. (2007). RNA sequence analysis defines Dicer's role in mouse embryonic stem cells. Proc Natl Acad Sci U S A 104, 18097-18102.

Carlile, M., Swan, D., Jackson, K., Preston-Fayers, K., Ballester, B., Flicek, P., and Werner, A. (2009). Strand selective generation of endo-siRNAs from the Na/phosphate transporter gene Slc34a1 in murine tissues. Nucleic Acids Research 37, 2274-2282.

Carmell, M.A., Girard, A., van de Kant, H.J.G., Bourc'his, D., Bestor, T.H., de Rooij, D.G., and Hannon, G.J. (2007). MIWI2 is essential for spermatogenesis and repression of transposons in the mouse male germline. Developmental Cell 12, 503-514.

Carmi, S., Borukhov, I., and Levanon, E.Y. (2011). Identification of Widespread Ultra-Edited Human RNAs. Plos Genetics 7, e1002317-e1002317.

Castanotto, D., Tommasi, S., Li, M., Li, H., Yanow, S., Pfeifer, G.P., and Rossi, J.J. (2005). Short hairpin RNA-directed cytosine $(\mathrm{CpG})$ methylation of the RASSF1A gene promoter in HeLa cells. Molecular Therapy 12, 179-183.

Chevillet, J.R., Kang, Q., Ruf, I.K., Briggs, H.A., Vojtech, L.N., Hughes, S.M., Cheng, H.H., Arroyo, J.D., Meredith, E.K., Gallichotte, E.N., et al. (2014). Quantitative and stoichiometric analysis of the microRNA content of exosomes. Proc Natl Acad Sci U S A 111, 14888-14893.

Chim, S.S., Shing, T.K., Hung, E.C., Leung, T.Y., Lau, T.K., Chiu, R.W., and Lo, Y.M. (2008). Detection and characterization of placental microRNAs in maternal plasma. Clinical chemistry 54, 482-490.

Cho, S., Park, J.S., and Kang, Y.K. (2014). AGO2 and SETDB1 cooperate in promoter-targeted transcriptional silencing of the androgen receptor gene. Nucleic Acids Research 42, 13545-13556.

Clerzius, G., Gelinas, J.F., Daher, A., Bonnet, M., Meurs, E.F., and Gatignol, A. (2009). ADAR1 Interacts with PKR during Human Immunodeficiency Virus Infection of Lymphocytes and Contributes to Viral Replication. Journal of Virology 83, 10119-10128.

Clop, A., Marcq, F., Takeda, H., Pirottin, D., Tordoir, X., Bibe, B., Bouix, J., Caiment, F., Elsen, J.M., Eychenne, F., et al. (2006). A mutation creating a potential illegitimate microRNA target site in the myostatin gene affects muscularity in sheep. Nature Genetics $38,813-818$. 
Cosentino, G.P., Venkatesan, S., Serluca, F.C., Green, S.R., Mathews, M.B., and Sonenberg, N. (1995). Double-stranded-RNA-dependent protein kinase and TAR RNA-binding protein form homo- and heterodimers in vivo. Proc Natl Acad Sci U S A 92, 9445-9449.

Cullen, B.R. (2006). Is RNA interference involved in intrinsic antiviral immunity in mammals? Nature Immunology 7, 563-567.

Cullen, B.R., Cherry, S., and tenOever, B.R. (2013). Is RNA interference a physiologically relevant innate antiviral immune response in mammals? Cell Host Microbe 14, 374-378.

Dawson, T.R., Sansam, C.L., and Emeson, R.B. (2004). Structure and sequence determinants required for the RNA editing of ADAR2 substrates. Journal of Biological Chemistry 279, 4941-4951.

de Veer, M.J., Sledz, C.A., and Williams, B.R. (2005). Detection of foreign RNA: implications for RNAi. Immunol Cell Biol 83, 224-228.

DeCerbo, J., and Carmichael, G.G. (2005). Retention and repression: fates of hyperedited RNAs in the nucleus. Current Opinion in Cell Biology 17, 302-308.

Deveson, I., Li, J.Y., and Millar, A.A. (2013). Expression of human ARGONAUTE 2 inhibits endogenous microRNA activity in Arabidopsis. Frontiers in Plant Science 4, 96-96.

Diallo, M., Arenz, C., Schmitz, K., Sandhoff, K., and Schepers, U. (2003). Long endogenous dsRNAs can induce complete gene silencing in mammalian cells and primary cultures. Oligonucleotides 13, 381-392.

Dismuke, W.M., Challa, P., Navarro, I., Stamer, W.D., and Liu, Y.T. (2015). Human aqueous humor exosomes. Experimental Eye Research 132, 73-77.

Doyle, M., Badertscher, L., Jaskiewicz, L., Guttinger, S., Jurado, S., Hugenschmidt, T., Kutay, U., and Filipowicz, W. (2013). The double-stranded RNA binding domain of human Dicer functions as a nuclear localization signal. RNA 19, 1238-1252.

Drake, M., Furuta, T., Suen, K.M., Gonzalez, G., Liu, B., Kalia, A., Ladbury, J.E., Fire, A.Z., Skeath, J.B., and Arur, S. (2014). A requirement for ERK-dependent Dicer phosphorylation in coordinating oocyte-to-embryo transition in C. elegans. Developmental Cell 31, 614-628.

Duursma, A.M., Kedde, M., Schrier, M., le Sage, C., and Agami, R. (2008). miR-148 targets human DNMT3b protein coding region. RNA 14, 872-877.

Duxbury, M.S., Ashley, S.W., and Whang, E.E. (2005). RNA interference: a mammalian SID-1 homologue enhances siRNA uptake and gene silencing efficacy in human cells. Biochem Biophys Res Commun 331, 459-463.

El-Andaloussi, S., Lee, Y., Lakhal-Littleton, S., Li, J., Seow, Y., Gardiner, C., Alvarez-Erviti, L., Sargent, I.L., and Wood, M.J.A. (2012). Exosome-mediated delivery of siRNA in vitro and in vivo. Nature Protocols 7, 2112-2126.

Elbashir, S.M., Harborth, J., Lendeckel, W., Yalcin, A., Weber, K., and Tuschl, T. (2001). Duplexes of 21-nucleotide RNAs mediate RNA interference in cultured mammalian cells. Nature 411, 494-498.

Fabbri, M., Garzon, R., Cimmino, A., Liu, Z., Zanesi, N., Callegari, E., Liu, S., Alder, H., Costinean, S., Fernandez-Cymering, C., et al. (2007). MicroRNA-29 family reverts aberrant methylation in lung cancer by targeting DNA methyltransferases 3A and 3B. Proc Natl Acad Sci U S A 104, $15805-15810$.

Farh, K.K., Grimson, A., Jan, C., Lewis, B.P., Johnston, W.K., Lim, L.P., Burge, C.B., and Bartel, D.P. (2005). The widespread impact of mammalian MicroRNAs on mRNA repression and evolution. Science 310, 1817-1821. 
Fenner, B.J., Thiagarajan, R., Chua, H.K., and Kwang, J. (2006). Betanodavirus B2 is an RNA interference antagonist that facilitates intracellular viral RNA accumulation. Journal of Virology 80 , 85-94.

Fire, A., Xu, S., Montgomery, M.K., Kostas, S.A., Driver, S.E., and Mello, C.C. (1998). Potent and specific genetic interference by double-stranded RNA in Caenorhabditis elegans. Nature 391, 806-811.

Flemr, M., Malik, R., Franke, V., Nejepinska, J., Sedlacek, R., Vlahovicek, K., and Svoboda, P. (2013). A Retrotransposon-Driven Dicer Isoform Directs Endogenous Small Interfering RNA Production in Mouse Oocytes. Cell 155, 807-816.

Francia, S., Michelini, F., Saxena, A., Tang, D., de Hoon, M., Anelli, V., Mione, M., Carninci, P., and di Fagagna, F.D. (2012). Site-specific DICER and DROSHA RNA products control the DNA-damage response. Nature 488, 231-+.

Fukagawa, T., Nogami, M., Yoshikawa, M., Ikeno, M., Okazaki, T., Takami, Y., Nakayama, T., and Oshimura, M. (2004). Dicer is essential for formation of the heterochromatin structure in vertebrate cells. Nature Cell Biology 6, 784-791.

Gagnon, K.T., Li, L.D., Chu, Y.J., Janowski, B.A., and Corey, D.R. (2014a). RNAi Factors Are Present and Active in Human Cell Nuclei. Cell Reports 6, 211-221.

Gagnon, K.T., Li, L.D., Janowski, B.A., and Corey, D.R. (2014b). Analysis of nuclear RNA interference in human cells by subcellular fractionation and Argonaute loading. Nature Protocols 9 , 2045-2060.

Gan, L., Anton, K.E., Masterson, B.A., Vincent, V.A., Ye, S., and Gonzalez-Zulueta, M. (2002). Specific interference with gene expression and gene function mediated by long dsRNA in neural cells. J Neurosci Methods 121, 151-157.

Gandy, S.Z., Linnstaedt, S.D., Muralidhar, S., Cashman, K.A., Rosenthal, L.J., and Casey, J.L. (2007). RNA editing of the human herpesvirus 8 kaposin transcript eliminates its transforming activity and is induced during lytic replication. Journal of Virology 81, 13544-13551.

Gantier, M.P., and Williams, B.R. (2007). The response of mammalian cells to double-stranded RNA. Cytokine Growth Factor Rev 18, 363-371.

Garcia-Lopez, J., Hourcade, J.D., and del Mazo, J. (2013). Reprogramming of microRNAs by adenosine-to-inosine editing and the selective elimination of edited microRNA precursors in mouse oocytes and preimplantation embryos. Nucleic Acids Research 41, 5483-5493.

Geiss, G., Jin, G., Guo, J., Bumgarner, R., Katze, M.G., and Sen, G.C. (2001). A comprehensive view of regulation of gene expression by double-stranded RNA-mediated cell signaling. Journal of Biological Chemistry 276, 30178-30182.

Glanzer, J., Miyashiro, K.Y., Sul, J.Y., Barrett, L., Belt, B., Haydon, P., and Eberwine, J. (2005). RNA splicing capability of live neuronal dendrites. Proc Natl Acad Sci U S A 102, 16859-16864.

Guang, S., Bochner, A.F., Burkhart, K.B., Burton, N., Pavelec, D.M., and Kennedy, S. (2010). Small regulatory RNAs inhibit RNA polymerase II during the elongation phase of transcription. Nature 465, 1097-1101.

Gullerova, M., and Proudfoot, N.J. (2012). Convergent transcription induces transcriptional gene silencing in fission yeast and mammalian cells. Nature Structural \& Molecular Biology 19, 1193-1201.

Haasnoot, J., de Vries, W., Geutjes, E.J., Prins, M., de Haan, P., and Berkhout, B. (2007). The Ebola virus VP35 protein is a suppressor of RNA silencing. Plos Pathogens 3, e86. 
Hammond, S.M., Bernstein, E., Beach, D., and Hannon, G.J. (2000). An RNA-directed nuclease mediates post-transcriptional gene silencing in Drosophila cells. Nature 404, 293-296.

Hauptmann, J., Schraivogel, D., Bruckmann, A., Manickavel, S., Jakob, L., Eichner, N., Pfaff, J., Urban, M., Sprunck, S., Hafner, M., et al. (2015). Biochemical isolation of Argonaute protein complexes by Ago-APP. Proc Natl Acad Sci U S A 112, 11841-11845.

Haussecker, D., and Proudfoot, N.J. (2005). Dicer-dependent turnover of intergenic transcripts from the human beta-globin gene cluster. Molecular and Cellular Biology 25, 9724-9733.

Hawkins, P.G., Santoso, S., Adams, C., Anest, V., and Morris, K.V. (2009). Promoter targeted small RNAs induce long-term transcriptional gene silencing in human cells. Nucleic Acids Research 37, 2984-2995.

Heraud-Farlow, J.E., and Walkley, C.R. (2016). The role of RNA editing by ADAR1 in prevention of innate immune sensing of self-RNA. J Mol Med (Berl).

Hock, J., Weinmann, L., Ender, C., Rudel, S., Kremmer, E., Raabe, M., Urlaub, H., and Meister, G. (2007). Proteomic and functional analysis of Argonaute-containing mRNA-protein complexes in human cells. EMBO Rep 8, 1052-1060.

Hong, J., Qian, Z.K., Shen, S.Y., Min, T.S., Tan, C., Xu, J.F., Zhao, Y.C., and Huang, W.D. (2005). High doses of siRNAs induce eri-1 and adar-1 gene expression and reduce the efficiency of RNA interference in the mouse. Biochemical Journal 390, 675-679.

Hornung, V., Ellegast, J., Kim, S., Brzozka, K., Jung, A., Kato, H., Poeck, H., Akira, S., Conzelmann, K.K., Schlee, M., et al. (2006). 5'-Triphosphate RNA is the ligand for RIG-I. Science 314, 994-997.

Houbaviy, H.B., Dennis, L., Jaenisch, R., and Sharp, P.A. (2005). Characterization of a highly variable eutherian rnicroRNA gene. RNA $11,1245-1257$.

Hu, J., Chen, Z., Xia, D., Wu, J., Xu, H., and Ye, Z.Q. (2012). Promoter-associated small double-stranded RNA interacts with heterogeneous nuclear ribonucleoprotein A2/B1 to induce transcriptional activation. Biochemical Journal 447, 407-416.

Hu, J., and Corey, D.R. (2007). Inhibiting gene expression with peptide nucleic acid (PNA)--peptide conjugates that target chromosomal DNA. Biochemistry 46, 7581-7589.

Huang, V., Zheng, J.S., Qi, Z.X., Wang, J., Place, R.F., Yu, J.W., Li, H., and Li, L.C. (2013a). Ago1 Interacts with RNA Polymerase II and Binds to the Promoters of Actively Transcribed Genes in Human Cancer Cells. Plos Genetics 9, e1003821-e1003821.

Huang, X.Y., Yuan, T.Z., Tschannen, M., Sun, Z.F., Jacob, H., Du, M.J., Liang, M.H., Dittmar, R.L., Liu, Y., Liang, M.Y., et al. (2013b). Characterization of human plasma-derived exosomal RNAs by deep sequencing. BMC Genomics 14, 319-319.

Hundley, H.A., Krauchuk, A.A., and Bass, B.L. (2008). C-elegans and H-sapiens mRNAs with edited 3 'UTRs are present on polysomes. RNA 14, 2050-2060.

Hunter, T., Hunt, T., Jackson, R.J., and Robertson, H.D. (1975). The characteristics of inhibition of protein synthesis by double-stranded ribonucleic acid in reticulocyte lysates. Journal of Biological Chemistry 250, 409-417.

Iavello, A., Frech, V.S.L., Gai, C., Deregibus, M.C., Quesenberry, P.J., and Camussi, G. (2016). Role of Alix in miRNA packaging during extracellular vesicle biogenesis. International Journal of Molecular Medicine 37, 958-966.

Iguchi, H., Kosaka, N., and Ochiya, T. (2010). Secretory microRNAs as a versatile communication tool. Communicative \& integrative biology 3, 478-481. 
Ingle, H., Kumar, S., Raut, A.A., Mishra, A., Kulkarni, D.D., Kameyama, T., Takaoka, A., Akira, S., and Kumar, H. (2015). The microRNA miR-485 targets host and influenza virus transcripts to regulate antiviral immunity and restrict viral replication. Science Signaling 8, ra126-ra126.

Ip, J., Canham, P., Choo, K.H.A., Inaba, Y., Jacobs, S.A., Kalitsis, P., Mattiske, D.M., Ng, J., Saffery, R., Wong, N.C., et al. (2012). Normal DNA Methylation Dynamics in DICER1-Deficient Mouse Embryonic Stem Cells. Plos Genetics 8, e1002919-e1002919.

Izumi, H., Tsuda, M., Sato, Y., Kosaka, N., Ochiya, T., Iwamoto, H., Namba, K., and Takeda, Y. (2015). Bovine milk exosomes contain microRNA and mRNA and are taken up by human macrophages. Journal of Dairy Science 98, 2920-2933.

Jang, J.H., Jung, J.S., Choi, J.I., and Kang, S.K. (2012). Nuclear Ago2/HSP60 Contributes to Broad Spectrum of hATSCs Function via Oct4 Regulation. Antioxidants \& Redox Signaling 16, 383-399.

Janowski, B.A., Huffman, K.E., Schwartz, J.C., Ram, R., Hardy, D., Shames, D.S., Minna, J.D., and Corey, D.R. (2005a). Inhibiting gene expression at transcription start sites in chromosomal DNA with antigene RNAs. Nature chemical biology 1, 216-222.

Janowski, B.A., Huffman, K.E., Schwartz, J.C., Ram, R., Nordsell, R., Shames, D.S., Minna, J.D., and Corey, D.R. (2006). Involvement of AGO1 and AGO2 in mammalian transcriptional silencing. Nature Structural \& Molecular Biology 13, 787-792.

Janowski, B.A., Kaihatsu, K., Huffman, K.E., Schwartz, J.C., Ram, R., Hardy, D., Mendelson, C.R., and Corey, D.R. (2005b). Inhibiting transcription of chromosomal DNA with antigene peptide nucleic acids. Nature chemical biology 1, 210-215.

Janowski, B.A., Younger, S.T., Hardy, D.B., Ram, R., Huffman, K.E., and Corey, D.R. (2007). Activating gene expression in mammalian cells with promoter-targeted duplex RNAs. Nature chemical biology 3, 166-173.

Jiang, F., Miller, M.T., and Marcotrigiano, J. (2011a). Structural Basis for RNA Recognition and Activation of RIG-I. Nucleic Acid Database.

Jiang, F.G., Ramanathan, A., Miller, M.T., Tang, G.Q., Gale, M., Patel, S.S., and Marcotrigiano, J. (2011b). Structural basis of RNA recognition and activation by innate immune receptor RIG-I. Nature 479, 423-U184.

Jiang, G., Zheng, L., Pu, J., Mei, H., Zhao, J., Huang, K., Zeng, F., and Tong, Q. (2012). Small RNAs Targeting Transcription Start Site Induce Heparanase Silencing through Interference with Transcription Initiation in Human Cancer Cells. Plos One 7, e31379-e31379.

John, B., Enright, A.J., Aravin, A., Tuschl, T., Sander, C., and Marks, D.S. (2004). Human MicroRNA targets. Plos Biology 2, e363.

Johnson, K.L., Price, B.D., Eckerle, L.D., and Ball, L.A. (2004). Nodamura virus nonstructural protein B2 can enhance viral RNA accumulation in both mammalian and insect cells. Journal of Virology 78, 6698-6704.

Jopling, C.L., Yi, M., Lancaster, A.M., Lemon, S.M., and Sarnow, P. (2005). Modulation of hepatitis C virus RNA abundance by a liver-specific MicroRNA. Science 309, 1577-1581.

Jose, A.M., and Hunter, C.P. (2007). Transport of sequence-specific RNA interference information between cells. Annu Rev Genet 41, 305-330.

Kaneda, M., Tang, F.C., O'Carroll, D., Lao, K.Q., and Surani, M.A. (2009). Essential role for Argonaute2 protein in mouse oogenesis. Epigenetics \& Chromatin 2, 9-9. 
Kanellopoulou, C., Muljo, S.A., Kung, A.L., Ganesan, S., Drapkin, R., Jenuwein, T., Livingston, D.M., and Rajewsky, K. (2005). Dicer-deficient mouse embryonic stem cells are defective in differentiation and centromeric silencing. Genes \& Development 19, 489-501.

Kato, H., Takeuchi, O., Sato, S., Yoneyama, M., Yamamoto, M., Matsui, K., Uematsu, S., Jung, A., Kawai, T., Ishii, K.J., et al. (2006). Differential roles of MDA5 and RIG-I helicases in the recognition of RNA viruses. Nature 441, 101-105.

Kawahara, Y., Zinshteyn, B., Chendrimada, T.P., Shiekhattar, R., and Nishikura, K. (2007a). RNA editing of the microRNA-151 precursor blocks cleavage by the Dicer-TRBP complex. EMBO Rep 8, 763-769.

Kawahara, Y., Zinshteyn, B., Sethupathy, P., Iizasa, H., Hatzigeorgiou, A.G., and Nishikura, K. (2007b). Redirection of silencing targets by adenosine-to-inosine editing of miRNAs. Science 315, 1137-1140.

Kawaji, H., Nakamura, M., Takahashi, Y., Sandelin, A., Katayama, S., Fukuda, S., Daub, C.O., Kai, C., Kawai, J., Yasuda, J., et al. (2008). Hidden layers of human small RNAs. BMC Genomics 9, 157.

Kawasaki, H., and Taira, K. (2004). Induction of DNA methylation and gene silencing by short interfering RNAs in human cells. Nature 431, 211-217.

Kim, B.S., Im, Y.B., Jung, S.J., Park, C.H., and Kang, S.K. (2012). Argonaute2 Regulation for K+ Channel-Mediated Human Adipose Tissue-Derived Stromal Cells Self-Renewal and Survival in Nucleus. Stem Cells and Development 21, 1736-1748.

Kim, B.S., Jung, J.S., Jang, J.H., Kang, K.S., and Kang, S.K. (2011). Nuclear Argonaute 2 regulates adipose tissue-derived stem cell survival through direct control of miR10b and selenoprotein N1 expression. Aging Cell 10, 277-291.

Kim, D.H., Saetrom, P., Snove, O., and Rossi, J.J. (2008). MicroRNA-directed transcriptional gene silencing in mammalian cells. Proc Natl Acad Sci U S A 105, 16230-16235.

Kim, D.H., Villeneuve, L.M., Morris, K.V., and Rossi, J.J. (2006). Argonaute-1 directs siRNA-mediated transcriptional gene silencing in human cells. Nature Structural \& Molecular Biology 13, 793-797.

Kim, J.W., Zhang, Y.H., Zern, M.A., Rossi, J.J., and Wu, J. (2007). Short hairpin RNA causes the methylation of transforming growth factor-beta receptor II promoter and silencing of the target gene in rat hepatic stellate cells. Biochem Biophys Res Commun 359, 292-297.

Koppers-Lalic, D., Hackenberg, M., Bijnsdorp, I.V., van Eijndhoven, M.A.J., Sadek, P., Sie, D., Zini, N., Middeldorp, J.M., Ylstra, B., de Menezes, R.X., et al. (2014). Nontemplated Nucleotide Additions Distinguish the Small RNA Composition in Cells from Exosomes. Cell Reports 8, 1649-1658.

Kozomara, A., and Griffiths-Jones, S. (2014). miRBase: annotating high confidence microRNAs using deep sequencing data. Nucleic Acids Res 42, D68-73.

Kropp, J., Salih, S.M., and Khatib, H. (2014). Expression of microRNAs in bovine and human pre-implantation embryo culture media. Frontiers in Genetics 5, 91-91.

Kumar, L., Verma, S., Vaidya, B., and Gupta, V. (2015). Exosomes: Natural Carriers for siRNA Delivery. Current Pharmaceutical Design 21, 4556-4565.

Lasser, C. (2012). Exosomal RNA as biomarkers and the therapeutic potential of exosome vectors. Expert Opinion on Biological Therapy 12, S189-S197.

Lawrie, C.H., Gal, S., Dunlop, H.M., Pushkaran, B., Liggins, A.P., Pulford, K., Banham, A.H., Pezzella, F., Boultwood, J., Wainscoat, J.S., et al. (2008). Detection of elevated levels of 
tumour-associated microRNAs in serum of patients with diffuse large B-cell lymphoma. British journal of haematology 141, 672-675.

Lecellier, C.H., Dunoyer, P., Arar, K., Lehmann-Che, J., Eyquem, S., Himber, C., Saib, A., and Voinnet, O. (2005). A cellular microRNA mediates antiviral defense in human cells. Science 308, 557-560.

Lee, Y., El Andaloussi, S., and Wood, M.J.A. (2012). Exosomes and microvesicles: extracellular vesicles for genetic information transfer and gene therapy. Human Molecular Genetics 21, R125-R134.

Lehmann, K.A., and Bass, B.L. (1999). The importance of internal loops within RNA substrates of ADAR1. Journal of Molecular Biology 291, 1-13.

Lewis, B.P., Shih, I.H., Jones-Rhoades, M.W., Bartel, D.P., and Burge, C.B. (2003). Prediction of mammalian microRNA targets. Cell 115, 787-798.

Li, H., Li, W.X., and Ding, S.W. (2002). Induction and suppression of RNA silencing by an animal virus. Science 296, 1319-1321.

Li, L.C., Okino, S.T., Zhao, H., Pookot, D., Place, R.F., Urakami, S., Enokida, H., and Dahiya, R. (2006). Small dsRNAs induce transcriptional activation in human cells. Proc Natl Acad Sci U S A 103, 17337-17342.

Li, W.X., Li, H., Lu, R., Li, F., Dus, M., Atkinson, P., Brydon, E.W., Johnson, K.L., Garcia-Sastre, A., Ball, L.A., et al. (2004). Interferon antagonist proteins of influenza and vaccinia viruses are suppressors of RNA silencing. Proc Natl Acad Sci U S A 101, 1350-1355.

Li, X.J., Lu, C., Stewart, M., Xu, H.Y., Strong, R.K., Igumenova, T., and Li, P.W. (2009a). Structural basis of double-stranded RNA recognition by the RIG-I like receptor MDA5. Archives of Biochemistry and Biophysics 488, 23-33.

Li, X.J., Ranjith-Kumar, C.T., Brooks, M.T., Dharmaiah, S., Herr, A.B., Kao, C., and Li, P.W. (2009b). The RIG-I-like Receptor LGP2 Recognizes the Termini of Double-stranded RNA. Journal of Biological Chemistry 284, 13881-13891.

Liang, X.H., and Crooke, S.T. (2011). Depletion of key protein components of the RISC pathway impairs pre-ribosomal RNA processing. Nucleic Acids Research 39, 4875-4889.

Lim, L.P., Lau, N.C., Garrett-Engele, P., Grimson, A., Schelter, J.M., Castle, J., Bartel, D.P., Linsley, P.S., and Johnson, J.M. (2005). Microarray analysis shows that some microRNAs downregulate large numbers of target mRNAs. Nature 433, 769-773.

Liu, J., Hu, J.X., and Corey, D.R. (2012). Expanding the action of duplex RNAs into the nucleus: redirecting alternative splicing. Nucleic Acids Research 40, 1240-1250.

Liu, J., Hu, J.X., Hicks, J.A., Prakash, T.P., and Corey, D.R. (2015). Modulation of Splicing by Single-Stranded Silencing RNAs. Nucleic Acid Therapeutics 25, 113-120.

Livengood, A.J., Wu, C.C.N., and Carson, D.A. (2007). Opposing roles of RNA receptors TLR3 and RIG-I in the inflammatory response to double-stranded RNA in a Kaposi's sarcoma cell line. Cellular Immunology 249, 55-62.

Lu, S.H., and Cullen, B.R. (2004). Adenovirus VA1 noncoding RNA can inhibit small interfering RNA and microRNA biogenesis. Journal of Virology 78, 12868-12876.

Luo, S.S., Ishibashi, O., Ishikawa, G., Ishikawa, T., Katayama, A., Mishima, T., Takizawa, T., Shigihara, T., Goto, T., Izumi, A., et al. (2009). Human Villous Trophoblasts Express and Secrete Placenta-Specific MicroRNAs into Maternal Circulation via Exosomes. Biology of Reproduction 81, 717-729.

Ma, J., Flemr, M., Stein, P., Berninger, P., Malik, R., Zavolan, M., Svoboda, P., and Schultz, R.M. (2010). MicroRNA Activity Is Suppressed in Mouse Oocytes. Current Biology 20, 265-270. 
Marques, J.T., Devosse, T., Wang, D., Zamanian-Daryoush, M., Serbinowski, P., Hartmann, R., Fujita, T., Behlke, M.A., and Williams, B.R.G. (2006). A structural basis for discriminating between self and nonself double-stranded RNAs in mammalian cells. Nature Biotechnology 24, 559-565.

Martinez, I., and Melero, J.A. (2002). A model for the generation of multiple A to G transitions in the human respiratory syncytial virus genome: predicted RNA secondary structures as substrates for adenosine cleaminases that act on RNA. Journal of General Virology 83, 1445-1455.

McCartney, S., Vermi, W., Gilfillan, S., Cella, M., Murphy, T.L., Schreiber, R.D., Murphy, K.M., and Colonna, M. (2009). Distinct and complementary functions of MDA5 and TLR3 in poly(I:C)-mediated activation of mouse NK cells. Journal of Experimental Medicine 206, 2967-2976.

McCartney, S.A., Thackray, L.B., Gitlin, L., Gilfillan, S., Virgin, H.W., and Colonna, M. (2008). MDA-5 recognition of a murine norovirus. Plos Pathogens 4, e1000108-e1000108.

Meister, G., Landthaler, M., Peters, L., Chen, P.Y., Urlaub, H., Luhrmann, R., and Tuschl, T. (2005). Identification of novel argonaute-associated proteins. Current Biology 15, 2149-2155.

Meister, G., and Tuschl, T. (2004). Mechanisms of gene silencing by double-stranded RNA. Nature $431,343-349$.

Meurs, E., Chong, K., Galabru, J., Thomas, N.S., Kerr, I.M., Williams, B.R., and Hovanessian, A.G. (1990). Molecular cloning and characterization of the human double-stranded RNA-activated protein kinase induced by interferon. Cell 62, 379-390.

Morris, K.V., Chan, S.W., Jacobsen, S.E., and Looney, D.J. (2004). Small interfering RNA-induced transcriptional gene silencing in human cells. Science 305, 1289-1292.

Morse, D.P., Aruscavage, P.J., and Bass, B.L. (2002). RNA hairpins in noncoding regions of human brain and Caenorhabditis elegans mRNA are edited by adenosine deaminases that act on RNA. Proc Natl Acad Sci U S A 99, 7906-7911.

Much, C., Auchynnikava, T., Pavlinic, D., Buness, A., Rappsilber, J., Benes, V., Allshire, R., and O'Carroll, D. (2016). Endogenous Mouse Dicer Is an Exclusively Cytoplasmic Protein. Plos Genetics 12, e1006095.

Murchison, E.P., Partridge, J.F., Tam, O.H., Cheloufi, S., and Hannon, G.J. (2005). Characterization of Dicer-deficient murine embryonic stem cells. Proc Natl Acad Sci U S A 102, 12135-12140.

Murchison, E.P., Stein, P., Xuan, Z., Pan, H., Zhang, M.Q., Schultz, R.M., and Hannon, G.J. (2007). Critical roles for Dicer in the female germline. Genes \& Development 21, 682-693.

Nachmani, D., Zimmermann, A., Djian, E., Weisblum, Y., Livneh, Y., Le, V.T.K., Galun, E., Horejsi, V., Isakov, O., Shomron, N., et al. (2014). MicroRNA Editing Facilitates Immune Elimination of HCMV Infected Cells. Plos Pathogens 10, e1003963-e1003963.

Napoli, S., Pastori, C., Magistri, M., Carbone, G.M., and Catapano, C.V. (2009). Promoter-specific transcriptional interference and c-myc gene silencing by siRNAs in human cells. EMBO J 28, 1708-1719.

Nejepinska, J., Malik, R., Filkowski, J., Flemr, M., Filipowicz, W., and Svoboda, P. (2012). dsRNA expression in the mouse elicits RNAi in oocytes and low adenosine deamination in somatic cells. Nucleic Acids Research 40, 399-413.

Nejepinska, J., Malik, R., Wagner, S., and Svoboda, P. (2014). Reporters transiently transfected into mammalian cells are highly sensitive to translational repression induced by dsRNA expression. Plos One 9, e87517.

Neve, J., Burger, K., Li, W.C., Hoque, M., Patel, R., Tian, B., Gullerova, M., and Furger, A. (2016). Subcellular RNA profiling links splicing and nuclear DICER1 to alternative cleavage and polyadenylation. Genome Research 26, 24-35. 
Nguyen, J., and Szoka, F.C. (2012). Nucleic Acid Delivery: The Missing Pieces of the Puzzle? Accounts of Chemical Research 45, 1153-1162.

Nie, Y.Z., Hammond, G.L., and Yang, J.H. (2007). Double-stranded RNA deaminase ADAR1 increases host susceptibility to virus infection. Journal of Virology 81, 917-923.

Nie, Y.Z., Zhao, Q.C., Su, Y.J., and Yang, J.H. (2004). Subcellular distribution of ADAR1 isoforms is synergistically determined by three nuclear discrimination signals and a regulatory motif. Journal of Biological Chemistry 279, 13249-13255.

Nishi, K., Nishi, A., Nagasawa, T., and Ui-Tei, K. (2013). Human TNRC6A is an Argonaute-navigator protein for microRNA-mediated gene silencing in the nucleus. RNA 19, 17-35.

Nishi, K., Takahashi, T., Suzawa, M., Miyakawa, T., Nagasawa, T., Ming, Y., Tanokura, M., and Ui-Tei, K. (2015). Control of the localization and function of a miRNA silencing component TNRC6A by Argonaute protein. Nucleic Acids Research 43, 9856-9873.

Nishikura, K. (2010). Functions and Regulation of RNA Editing by ADAR Deaminases. In Annual Review of Biochemistry, Vol 79, pp. 321-349.

Nishikura, K. (2016). A-to-I editing of coding and non-coding RNAs by ADARs. Nature Reviews Molecular Cell Biology 17, 83-96.

Nishikura, K., Yoo, C., Kim, U., Murray, J.M., Estes, P.A., Cash, F.E., and Liebhaber, S.A. (1991). Substrate specificity of the dsRNA unwinding/modifying activity. EMBO J 10, 3523-3532.

Novellino, L., Rossi, R.L., Bonino, F., Cavallone, D., Abrignani, S., Pagani, M., and Brunetto, M.R. (2012). Circulating Hepatitis B Surface Antigen Particles Carry Hepatocellular microRNAs. Plos One 7, e31952-e31952.

Ohnishi, Y., Totoki, Y., Toyoda, A., Watanabe, T., Yamamoto, Y., Tokunaga, K., Sakaki, Y., Sasaki, H., and Hohjoh, H. (2010). Small RNA class transition from siRNA/piRNA to miRNA during pre-implantation mouse development. Nucleic Acids Research 38, 5141-5151.

Ohrt, T., Merkle, D., Birkenfeld, K., Echeverri, C.J., and Schwille, P. (2006). In situ fluorescence analysis demonstrates active siRNA exclusion from the nucleus by Exportin 5. Nucleic Acids Research 34, 1369-1380.

Ohrt, T., Muetze, J., Staroske, W., Weinmann, L., Hock, J., Crell, K., Meister, G., and Schwille, P. (2008). Fluorescence correlation spectroscopy and fluorescence cross-correlation spectroscopy reveal the cytoplasmic origination of loaded nuclear RISC in vivo in human cells. Nucleic Acids Research 36, 6439-6449.

Ohrt, T., Muetze, J., Svoboda, P., and Schwille, P. (2012). Intracellular Localization and Routing of miRNA and RNAi Pathway Components. Curr Top Med Chem 12, 79-88.

Ostermann, E., Tuddenham, L., Macquin, C., Alsaleh, G., Schreiber-Becker, J., Tanguy, M., Bahram, S., Pfeffer, S., and Georgel, P. (2012). Deregulation of Type I IFN-Dependent Genes Correlates with Increased Susceptibility to Cytomegalovirus Acute Infection of Dicer Mutant Mice. Plos One 7, e43744-e43744.

Parameswaran, P., Sklan, E., Wilkins, C., Burgon, T., Samuel, M.A., Lu, R., Ansel, K.M., Heissmeyer, V., Einav, S., Jackson, W., et al. (2010). Six RNA Viruses and Forty-One Hosts: Viral Small RNAs and Modulation of Small RNA Repertoires in Vertebrate and Invertebrate Systems. Plos Pathogens 6, e1000764-e1000764.

Park, H.S., Davies, M.V., Langland, J.O., Chang, H.W., Nam, Y.S., Tartaglia, J., Paoletti, E., Jacobs, B.L., Kaufman, R.J., and Venkatesan, S. (1994). TAR RNA-binding protein is an inhibitor of the interferon-induced protein kinase PKR. Proc Natl Acad Sci U S A 91, 4713-4717. 
Patel, R.C., and Sen, G.C. (1998). PACT, a protein activator of the interferon-induced protein kinase, PKR. EMBO J 17, 4379-4390.

Pegtel, D.M., van de Garde, M.D.B., and Middeldorp, J.M. (2011). Viral miRNAs exploiting the endosomal-exosomal pathway for intercellular cross-talk and immune evasion. Biochimica Et Biophysica Acta-Gene Regulatory Mechanisms 1809, 715-721.

Peng, Z.Y., Cheng, Y.B., Tan, B.C.M., Kang, L., Tian, Z.J., Zhu, Y.K., Zhang, W.W., Liang, Y., Hu, X.D., Tan, X.M., et al. (2012). Comprehensive analysis of RNA-Seq data reveals extensive RNA editing in a human transcriptome. Nature Biotechnology 30, 253-+.

Pfeffer, S., Sewer, A., Lagos-Quintana, M., Sheridan, R., Sander, C., Grasser, F.A., van Dyk, L.F., Ho, C.K., Shuman, S., Chien, M., et al. (2005). Identification of microRNAs of the herpesvirus family. Nature Methods 2, 269-276.

Pfeffer, S., Zavolan, M., Grasser, F.A., Chien, M., Russo, J.J., Ju, J., John, B., Enright, A.J., Marks, D., Sander, C., et al. (2004). Identification of virus-encoded microRNAs. Science 304, 734-736.

Pichlmair, A., Schulz, O., Tan, C.P., Naslund, T.I., Liljestrom, P., Weber, F., and Reis e Sousa, C. (2006). RIG-I-mediated antiviral responses to single-stranded RNA bearing 5'-phosphates. Science 314, 997-1001.

Place, R.F., Li, L.C., Pookot, D., Noonan, E.J., and Dahiya, R. (2008). MicroRNA-373 induces expression of genes with complementary promoter sequences. Proc Natl Acad Sci U S A 105, 1608-1613.

Polson, A.G., and Bass, B.L. (1994). Preferential selection of adenosines for modification by double-stranded RNA adenosine deaminase. EMBO J 13, 5701-5711.

Poulsen, H., Jorgensen, R., Heding, A., Nielsen, F.C., Bonven, B., and Egebjerg, J. (2006). Dimerization of ADAR2 is mediated by the double-stranded RNA binding domain. RNA 12, 1350-1360.

Puthenveetil, S., Whitby, L., Ren, J., Kelnar, K., Krebs, J.F., and Beal, P.A. (2006). Controlling activation of the RNA-dependent protein kinase by siRNAs using site-specific chemical modification. Nucleic Acids Research 34, 4900-4911.

Rak, J. (2013). Extracellular vesicles - biomarkers and effectors of the cellular interactome in cancer. Frontiers in Pharmacology 4, 21-21.

Reynolds, A., Anderson, E.M., Vermeulen, A., Fedorov, Y., Robinson, K., Leake, D., Karpilow, J., Marshall, W.S., and Khvorova, A. (2006). Induction of the interferon response by siRNA is cell type- and duplex length-dependent. RNA 12, 988-993.

Rice, G.I., Kasher, P.R., Forte, G.M.A., Mannion, N.M., Greenwood, S.M., Szynkiewicz, M., Dickerson, J.E., Bhaskar, S.S., Zampini, M., Briggs, T.A., et al. (2012). Mutations in ADAR1 cause Aicardi-Goutieres syndrome associated with a type I interferon signature. Nature Genetics 44 , 1243-1248.

Robb, G.B., Brown, K.M., Khurana, J., and Rana, T.M. (2005). Specific and potent RNAi in the nucleus of human cells. Nature Structural \& Molecular Biology 12, 133-137.

Rudel, S., Flatley, A., Weinmann, L., Kremmer, E., and Meister, G. (2008). A multifunctional human Argonaute2-specific monoclonal antibody. RNA 14, 1244-1253.

Sadler, A.J., and Williams, B.R. (2007). Structure and function of the protein kinase R. Current topics in microbiology and immunology 316, 253-292.

Salameh, A., Lee, A.K., Cardo-Vila, M., Nunes, D.N., Efstathiou, E., Staquicini, F.I., Dobroff, A.S., Marchio, S., Navone, N.M., Hosoya, H., et al. (2015). PRUNE2 is a human prostate cancer suppressor regulated by the intronic long noncoding RNA PCA3. Proc Natl Acad Sci U S A 112, 8403-8408. 
Samuel, C.E. (2011). Adenosine deaminases acting on RNA (ADARs) are both antiviral and proviral. Virology 411, 180-193.

Sanchez-Vargas, I., Scott, J.C., Poole-Smith, B.K., Franz, A.W., Barbosa-Solomieu, V., Wilusz, J., Olson, K.E., and Blair, C.D. (2009). Dengue virus type 2 infections of Aedes aegypti are modulated by the mosquito's RNA interference pathway. Plos Pathogens 5, e1000299.

Scadden, A.D. (2005). The RISC subunit Tudor-SN binds to hyper-edited double-stranded RNA and promotes its cleavage. Nature Structural \& Molecular Biology 12, 489-496.

Scadden, A.D., and Smith, C.W. (2001). RNAi is antagonized by A-->I hyper-editing. EMBO Rep 2, 1107-1111.

Schlee, M., and Hartmann, G. (2010). The Chase for the RIG-I Ligand-Recent Advances. Molecular Therapy $18,1254-1262$.

Schwartz, T., Rould, M.A., Lowenhaupt, K., Herbert, A., and Rich, A. (1999). Crystal structure of the $\mathrm{Z}$ alpha domain of the human editing enzyme ADAR1 bound to left-handed Z-DNA. Science 284, 1841-1845.

Sen, A., Pruijssers, A.J., Dermody, T.S., Garcia-Sastre, A., and Greenberg, H.B. (2011). The Early Interferon Response to Rotavirus Is Regulated by PKR and Depends on MAVS/IPS-1, RIG-I, MDA-5, and IRF3. Journal of Virology 85, 3717-3732.

Seo, G.J., Kincaid, R.P., Phanaksri, T., Burke, J.M., Pare, J.M., Cox, J.E., Hsiang, T.Y., Krug, R.M., and Sullivan, C.S. (2013). Reciprocal Inhibition between Intracellular Antiviral Signaling and the RNAi Machinery in Mammalian Cells. Cell Host \& Microbe 14, 435-445.

Shapiro, J.S., Schmid, S., Aguado, L.C., Sabin, L.R., Yasunaga, A., Shim, J.V., Sachs, D., Cherry, S., and Tenoever, B.R. (2014). Drosha as an interferon-independent antiviral factor. Proc Natl Acad Sci U S A 111, 7108-7113.

Sharma, A. (2015). Transgenerational epigenetic inheritance: resolving uncertainty and evolving biology. Biomolecular concepts 6, 87-103.

Sharma, N.R., Wang, X.H., Majerciak, V., Ajiro, M., Kruhlak, M., Meyers, C., and Zheng, Z.M. (2016). Cell Type- and Tissue Context-dependent Nuclear Distribution of Human Ago2. Journal of Biological Chemistry 291, 2302-2309.

Shi, H., Tschudi, C., and Ullu, E. (2006). Functional replacement of Trypanosoma brucei Argonaute by the human slicer Argonaute2. RNA 12, 943-947.

Shinagawa, T., and Ishii, S. (2003). Generation of Ski-knockdown mice by expressing a long double-strand RNA from an RNA polymerase II promoter. Genes \& Development 17, 1340-1345.

Shtam, T.A., Kovalev, R.A., Varfolomeeva, E.Y., Makarov, E.M., Kil, Y.V., and Filatov, M.V. (2013). Exosomes are natural carriers of exogenous siRNA to human cells in vitro. Cell Communication and Signaling 11, 88-88.

Sinkkonen, L., Hugenschmidt, T., Berninger, P., Gaidatzis, D., Mohn, F., Artus-Revel, C.G., Zavolan, M., Svoboda, P., and Filipowicz, W. (2008). MicroRNAs control de novo DNA methylation through regulation of transcriptional repressors in mouse embryonic stem cells. Nature Structural \& Molecular Biology 15, 259-267.

Sinkkonen, L., Hugenschmidt, T., Filipowicz, W., and Svoboda, P. (2010). Dicer Is Associated with Ribosomal DNA Chromatin in Mammalian Cells. Plos One 5, e12175-e12175.

Slater, L., Bartlett, N.W., Haas, J.J., Zhu, J., Message, S.D., Walton, R.P., Sykes, A., Dahdaleh, S., Clarke, D.L., Belvisi, M.G., et al. (2010). Co-ordinated Role of TLR3, RIG-I and MDA5 in the Innate Response to Rhinovirus in Bronchial Epithelium. Plos Pathogens 6, e1001178-e1001178. 
Smalheiser, N.R., Lugli, G., Thimmapuram, J., Cook, E.H., and Larson, J. (2011). Endogenous siRNAs and noncoding RNA-derived small RNAs are expressed in adult mouse hippocampus and are up-regulated in olfactory discrimination training. RNA 17, 166-181.

Stefl, R., Oberstrass, F.C., Hood, J.L., Jourdan, M., Zimmermann, M., Skrisovska, L., Maris, C., Peng, L., Hofr, C., Emeson, R.B., et al. (2010). The solution structure of the ADAR2 dsRBM-RNA complex reveals a sequence-specific readout of the minor groove. Cell 143, 225-237.

Stein, P., Rozhkov, N.V., Li, F., Cardenas, F.L., Davydenk, O., Vandivier, L.E., Gregory, B.D., Hannon, G.J., and Schultz, R.M. (2015). Essential Role for Endogenous siRNAs during Meiosis in Mouse Oocytes. Plos Genetics 11.

Stein, P., Zeng, F., Pan, H., and Schultz, R.M. (2005). Absence of non-specific effects of RNA interference triggered by long double-stranded RNA in mouse oocytes. Developmental Biology 286, 464-471.

Suh, M.R., Lee, Y., Kim, J.Y., Kim, S.K., Moon, S.H., Lee, J.Y., Cha, K.Y., Chung, H.M., Yoon, H.S., Moon, S.Y., et al. (2004). Human embryonic stem cells express a unique set of microRNAs. Developmental Biology 270, 488-498.

Suh, N., Baehner, L., Moltzahn, F., Melton, C., Shenoy, A., Chen, J., and Blelloch, R. (2010). MicroRNA Function Is Globally Suppressed in Mouse Oocytes and Early Embryos. Current Biology 20, 271-277.

Suk, K., Choi, J., Suzuki, Y., Ozturk, S.B., Mellor, J.C., Wong, K.H., MacKay, J.L., Gregory, R.I., and Roth, F.P. (2011). Reconstitution of human RNA interference in budding yeast. Nucleic Acids Research 39, E43-U59.

Sullivan, C.S., Grundhoff, A.T., Tevethia, S., Pipas, J.M., and Ganem, D. (2005). SV40-encoded microRNAs regulate viral gene expression and reduce susceptibility to cytotoxic $\mathrm{T}$ cells. Nature 435, 682-686.

Suzuki, K., Juelich, T., Lim, H., Ishida, T., Watanebe, T., Cooper, D.A., Rao, S., and Kelleher, A.D. (2008). Closed chromatin architecture is induced by an RNA duplex targeting the HIV-1 promoter region. Journal of Biological Chemistry 283, 23353-23363.

Svoboda, P., Stein, P., Anger, M., Bernstein, E., Hannon, G.J., and Schultz, R.M. (2004). RNAi and expression of retrotransposons MuERV-L and IAP in preimplantation mouse embryos. Developmental Biology 269, 276-285.

Swahari, V., Nakamura, A., Baran-Gale, J., Garcia, I., Crowther, A.J., Sons, R., Gershon, T.R., Hammond, S., Sethupathy, P., and Deshmukh, M. (2016). Essential Function of Dicer in Resolving DNA Damage in the Rapidly Dividing Cells of the Developing and Malignant Cerebellum. Cell Reports 14, 216-224.

Taira, K. (2006). Induction of DNA methylation and gene silencing by short interfering RNAs in human cells. Nature 441, 1176.

Tam, O.H., Aravin, A.A., Stein, P., Girard, A., Murchison, E.P., Cheloufi, S., Hodges, E., Anger, M., Sachidanandam, R., Schultz, R.M., et al. (2008). Pseudogene-derived small interfering RNAs regulate gene expression in mouse oocytes. Nature 453, 534-U538.

Tan, G.S., Garchow, B.G., Liu, X.H., Yeung, J., Morris, J.P., Cuellar, T.L., McManus, M.T., and Kiriakidou, M. (2009a). Expanded RNA-binding activities of mammalian Argonaute 2. Nucleic Acids Research 37, 7533-7545. 
Tan, Y.L., Zhang, B., Wu, T., Skogerbo, G., Zhu, X.P., Guo, X.Q., He, S.M., and Chen, R.S. (2009b). Transcriptional inhibiton of Hoxd4 expression by miRNA-10a in human breast cancer cells. BMC Molecular Biology 10, 12-12.

Tang, F., Kaneda, M., O’Carroll, D., Hajkova, P., Barton, S.C., Sun, Y.A., Lee, C., Tarakhovsky, A., Lao, K.Q., and Surani, M.A. (2007). Maternal microRNAs are essential for mouse zygotic development. Genes \& Development 21, 644-648.

Thuringer, D., Jego, G., Berthenet, K., Hammann, A., Solary, E., and Garrido, C. (2016). Gap junction-mediated transfer of miR-145-5p from microvascular endothelial cells to colon cancer cells inhibits angiogenesis. Oncotarget.

Ting, A.H., Schuebel, K.E., Herman, J.G., and Baylin, S.B. (2005). Short double-stranded RNA induces transcriptional gene silencing in human cancer cells in the absence of DNA methylation. Nature Genetics 37, 906-910.

Ting, A.H., Suzuki, H., Cope, L., Schuebel, K.E., Lee, B.H., Toyota, M., Imai, K., Shinomura, Y., Tokino, T., and Baylin, S.B. (2008). A requirement for DICER to maintain full promoter CpG island hypermethylation in human cancer cells. Cancer Research 68, 2570-2575.

Toth, K.F., Pezic, D., Stuwe, E., and Webster, A. (2016). The piRNA Pathway Guards the Germline Genome Against Transposable Elements. In Non-Coding Rna and the Reproductive System, pp. 51-77.

Tran, N., Raponi, M., Dawes, I.W., and Arndt, G.M. (2004). Control of specific gene expression in mammalian cells by co-expression of long complementary RNAs. FEBS Letters 573, 127-134.

Turchinovich, A., Weiz, L., Langheinz, A., and Burwinkel, B. (2011). Characterization of extracellular circulating microRNA. Nucleic Acids Research 39, 7223-7233.

Valen, E., Preker, P., Andersen, P.R., Zhao, X., Chen, Y., Ender, C., Dueck, A., Meister, G., Sandelin, A., and Jensen, T.H. (2011). Biogenic mechanisms and utilization of small RNAs derived from human protein-coding genes. Nature Structural \& Molecular Biology 18, 1075-1082.

Vesely, C., Tauber, S., Sedlazeck, F.J., von Haeseler, A., and Jantsch, M.F. (2012). Adenosine deaminases that act on RNA induce reproducible changes in abundance and sequence of embryonic miRNAs. Genome Research 22, 1468-1476.

Wahlgren, J., Karlson, T.D., Brisslert, M., Sani, F.V., Telemo, E., Sunnerhagen, P., and Valadi, H. (2012). Plasma exosomes can deliver exogenous short interfering RNA to monocytes and lymphocytes. Nucleic Acids Research 40, e130-e130.

Wahlgren, J., Statello, L., Skogberg, G., Telemo, E., and Valadi, H. (2016). Delivery of Small Interfering RNAs to Cells via Exosomes. In Sirna Delivery Methods: Methods and Protocols, pp. 105-125.

Wang, J., Huang, V., Ye, L., Barcena, A., Lin, G., Lue, T.F., and Li, L.-C. (2015a). Identification of Small Activating RNAs that Enhance Endogenous OCT4 Expression in Human Mesenchymal Stem Cells. Stem Cells and Development 24, 345-353.

Wang, S.Q., Liu, D.Y., Jin, R., Zhu, Y.P., and Xu, A.E. (2015b). Differential Responses of Normal Human Melanocytes to Intra- and Extracellular dsRNA. DNA and Cell Biology 34, 391-399.

Wang, X.H., Aliyari, R., Li, W.X., Li, H.W., Kim, K., Carthew, R., Atkinson, P., and Ding, S.W. (2006). RNA interference directs innate immunity against viruses in adult Drosophila. Science $312,452-454$.

Wang, Y., Mercier, R., Hobman, T.C., and LaPointe, P. (2013). Regulation of RNA interference by Hsp90 is an evolutionarily conserved process. Biochimica Et Biophysica Acta-Molecular Cell Research 1833, 2673-2681. 
Wang, Y.M., Medvid, R., Melton, C., Jaenisch, R., and Blelloch, R. (2007). DGCR8 is essential for microRNA biogenesis and silencing of embryonic stem cell self-renewal. Nature Genetics 39, 380-385. Watanabe, T., Takeda, A., Tsukiyama, T., Mise, K., Okuno, T., Sasaki, H., Minami, N., and Imai, H. (2006). Identification and characterization of two novel classes of small RNAs in the mouse germline: retrotransposon-derived siRNAs in oocytes and germline small RNAs in testes. Genes \& Development 20, 1732-1743.

Watanabe, T., Totoki, Y., Toyoda, A., Kaneda, M., Kuramochi-Miyagawa, S., Obata, Y., Chiba, H., Kohara, Y., Kono, T., Nakano, T., et al. (2008). Endogenous siRNAs from naturally formed dsRNAs regulate transcripts in mouse oocytes. Nature 453, 539-U539.

Wee, L.M., Flores-Jasso, C.F., Salomon, W.E., and Zamore, P.D. (2012). Argonaute Divides Its RNA Guide into Domains with Distinct Functions and RNA-Binding Properties. Cell 151, 1055-1067.

Wei, H.B., Zhou, B., Zhang, F., Tu, Y.Y., Hu, Y.N., Zhang, B.G., and Zhai, Q.W. (2013). Profiling and Identification of Small rDNA-Derived RNAs and Their Potential Biological Functions. Plos One 8, e56842-e56842.

Wei, W., Ba, Z.Q., Gao, M., Wu, Y., Ma, Y.T., Amiard, S., White, C.I., Danielsen, J.M.R., Yang, Y.G., and Qi, Y.J. (2012). A Role for Small RNAs in DNA Double-Strand Break Repair. Cell 149, 101-112.

Weinberg, M.S., Villeneuve, L.M., Ehsani, A., Amarzguioui, M., Aagaard, L., Chen, Z.X., Riggs, A.D., Rossi, J.J., and Morris, K.V. (2006). The antisense strand of small interfering RNAs directs histone methylation and transcriptional gene silencing in human cells. RNA 12, 256-262.

Weinmann, L., Hock, J., Ivacevic, T., Ohrt, T., Mutze, J., Schwille, P., Kremmer, E., Benes, V., Urlaub, H., and Meister, G. (2009). Importin 8 is a gene silencing factor that targets argonaute proteins to distinct mRNAs. Cell 136, 496-507.

Weissbach, R., and Scadden, A.D.J. (2012). Tudor-SN and ADAR1 are components of cytoplasmic stress granules. RNA 18, 462-471.

White, E., Schlackow, M., Kamieniarz-Gdula, K., Proudfoot, N.J., and Gullerova, M. (2014). Human nuclear Dicer restricts the deleterious accumulation of endogenous double-stranded RNA. Nature Structural \& Molecular Biology 21, 552-559.

Wilkins, C., Dishongh, R., Moore, S.C., Whitt, M.A., Chow, M., and Machaca, K. (2005). RNA interference is an antiviral defence mechanism in Caenorhabditis elegans. Nature 436, 1044-1047.

Wolfrum, C., Shi, S., Jayaprakash, K.N., Jayaraman, M., Wang, G., Pandey, R.K., Rajeev, K.G., Nakayama, T., Charrise, K., Ndungo, E.M., et al. (2007). Mechanisms and optimization of in vivo delivery of lipophilic siRNAs. Nature Biotechnology 25, 1149-1157.

Wong, S.K., and Lazinski, D.W. (2002). Replicating hepatitis delta virus RNA is edited in the nucleus by the small form of ADAR1. Proc Natl Acad Sci U S A 99, 15118-15123.

Wu, G.P., Yang, G.H., Zhang, R.X., Xu, G.Y., Zhang, L., Wen, W., Lu, J.B., Liu, J.Y., and Yu, Y. (2015a). Altered microRNA Expression Profiles of Extracellular Vesicles in Nasal Mucus From Patients With Allergic Rhinitis. Allergy Asthma \& Immunology Research 7, 449-457.

Wu, W.X., Zhang, W., Duggan, E.S., Booth, J.L., Zou, M.H., and Metcalf, J.P. (2015b). RIG-I and TLR3 are both required for maximum interferon induction by influenza virus in human lung alveolar epithelial cells. Virology 482, 181-188.

Xu, S., Xue, C.Y., Li, J.P., Bi, Y.Z., and Cao, Y.C. (2011). Marek's Disease Virus Type 1 MicroRNA miR-M3 Suppresses Cisplatin-Induced Apoptosis by Targeting SMAD2 of the Transforming Growth Factor Beta Signal Pathway. Journal of Virology 85, 276-285. 
Yang, N., and Kazazian, H.H., Jr. (2006). L1 retrotransposition is suppressed by endogenously encoded small interfering RNAs in human cultured cells. Nature Structural \& Molecular Biology 13, $763-771$.

Yang, S., Tutton, S., Pierce, E., and Yoon, K. (2001). Specific double-stranded RNA interference in undifferentiated mouse embryonic stem cells. Molecular and Cellular Biology 21, 7807-7816.

Yang, W.D., Chendrimada, T.P., Wang, Q.D., Higuchi, M., Seeburg, P.H., Shiekhattar, R., and Nishikura, K. (2006a). Modulation of microRNA processing and expression through RNA editing by ADAR deaminases. Nature Structural \& Molecular Biology 13, 13-21.

Yang, W.D., Wang, Q.D., Howell, K.L., Lee, J.T., Cho, D.S.C., Murray, J.M., and Nishikura, K. (2005). ADAR1 RNA deaminase limits short interfering RNA efficacy in mammalian cells. Journal of Biological Chemistry 280, 3946-3953.

Yang, X., Murthy, V., Schultz, K., Tatro, J.B., Fitzgerald, K.A., and Beasley, D. (2006b). Toll-like receptor 3 signaling evokes a proinflammatory and proliferative phenotype in human vascular smooth muscle cells. American Journal of Physiology-Heart and Circulatory Physiology 291, H2334-H2343.

Yi, C.E., Bekker, J.M., Miller, G., Hill, K.L., and Crosbie, R.H. (2003). Specific and potent RNA interference in terminally differentiated myotubes. Journal of Biological Chemistry 278, 934-939.

Yoneyama, M., Kikuchi, M., Natsukawa, T., Shinobu, N., Imaizumi, T., Miyagishi, M., Taira, K., Akira, S., and Fujita, T. (2004). The RNA helicase RIG-I has an essential function in double-stranded RNA-induced innate antiviral responses. Nature Immunology 5, 730-737.

Yoon, Y.J., Kim, O.Y., and Gho, Y.S. (2014). Extracellular vesicles as emerging intercellular communicasomes. BMB Reports 47, 531-539.

Younger, S.T., and Corey, D.R. (2011). Transcriptional gene silencing in mammalian cells by miRNA mimics that target gene promoters. Nucleic Acids Research 39, 5682-5691.

Zamore, P.D., Tuschl, T., Sharp, P.A., and Bartel, D.P. (2000). RNAi: double-stranded RNA directs the ATP-dependent cleavage of mRNA at 21 to 23 nucleotide intervals. Cell 101, 25-33.

Zeng, Y., Wagner, E.J., and Cullen, B.R. (2002). Both natural and designed micro RNAs can inhibit the expression of cognate mRNAs when expressed in human cells. Molecular Cell 9, 1327-1333.

Zhang, L., Hou, D., Chen, X., Li, D., Zhu, L., Zhang, Y., Li, J., Bian, Z., Liang, X., Cai, X., et al. (2012). Exogenous plant MIR168a specifically targets mammalian LDLRAP1: evidence of cross-kingdom regulation by microRNA. Cell Research 22, 107-126.

Zhang, M.X., Zhang, C., Shen, Y.H., Wang, J., Li, X.N., Chen, L., Zhang, Y., Coselli, J.S., and Wang, X.L. (2008a). Effect of 27nt small RNA on endothelial nitric-oxide synthase expression. Molecular Biology of the Cell 19, 3997-4005.

Zhang, M.X., Zhang, C., Shen, Y.H., Wang, J., Li, X.N., Zhang, Y., Coselli, J., and Wang, X.L. (2008b). Biogenesis of short intronic repeat 27nt small RNA from endothelial nitric oxide synthase gene. Journal of Biological Chemistry.

Zhang, X.Z., Li, H.T., Burnett, J.C., and Rossi, J.J. (2014). The role of antisense long noncoding RNA in small RNA-triggered gene activation. RNA 20, 1916-1928.

Zheng, X.F., and Bevilacqua, P.C. (2004). Activation of the protein kinase PKR by short double-stranded RNAs with single-stranded tails. RNA 10, 1934-1945.

Zheng, Z.M., Tang, S.A., and Tao, M.F. (2005). Development of resistance to RNAi in mammalian cells. In Strategies for Silencing Gene Expression, pp. 105-118. 